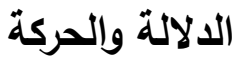 \\ دراسة الأفعال الحركية الماضية في سورة البقرة
}

\author{
مالك يحتود
}


يتتاول هذا البحث أفعال الحركة الماضية في سورة البقرة ، دراسة دلالية ـ وذلك من أمرين، أولهما: إنّ محتوى القرآن محتوى حركي يتوازى مع حركة العلم النشطة، وهو مساير لكل زمان ومكان، فكل جيل سيجد فيه منويً معرفياً جديداً. وثانيهما: أنه قد ارتبط بأعظم حركة في تاريخ الإنسانية. واقظت طبيعة البحث أن يقسم إلى قسمين: الأول نظري: وققت فيه عند مفهوم الفعل عند القدماء وزمن الفعل في القرآن الكريم الذي بدا ديناميكياً يتداخل فيه الماضي مع الحاضر مع هع

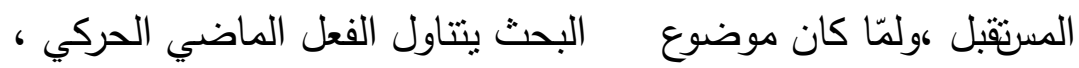

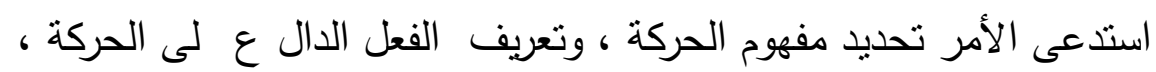
وعرض أفعال من القرآن الكريم برزت الحركة فيها بشلكلى واضح.

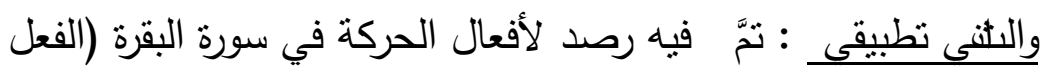

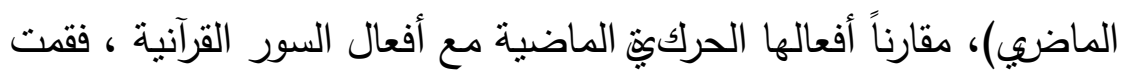

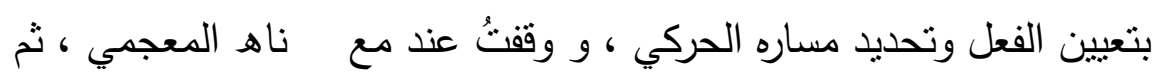
بحثتُ عن عدد المرات التي ورد فيها الفعل ف ي القرآن الكريم ، ثم تتبعت بعد ذلك دلالة الفعل الماضي ... هذه الدلالة التي قد تلك ون حقيقية لم تتجاوز المعنى المعجمي ، وقد تكون تخصصت باستخدامها القرآني ، أو قد

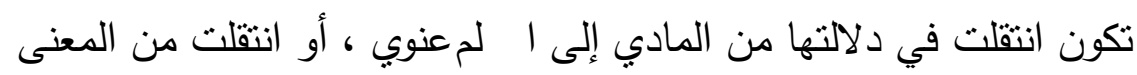

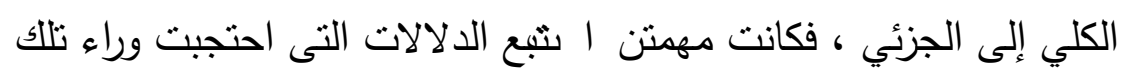

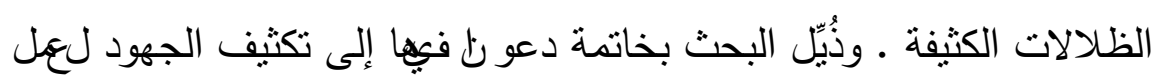

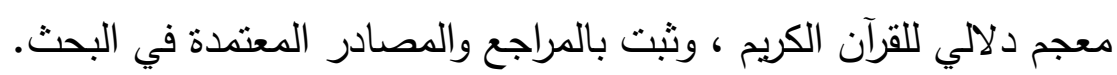




\section{مفهوم الفعل}

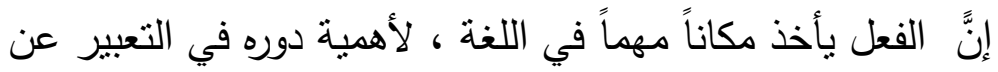

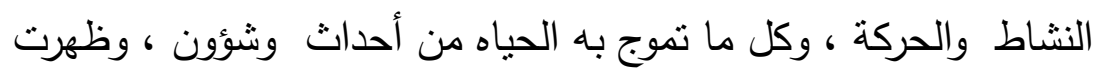

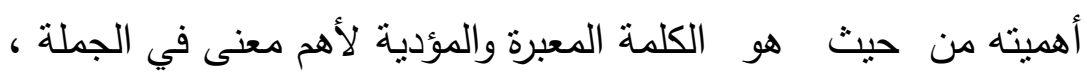

بالإضافة إلى ارتباط بقية عناصر التركيب به .

ونال الفعل اهتمام أهل اللغة القدماء الذين كانوا يرون أنّ الفعل

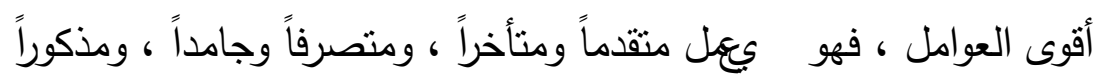

ومحذوفاً ، واستبحر القدماء في نفصيل نظرية العامل (1).

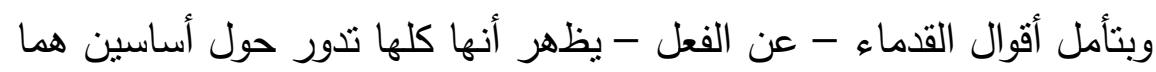

أ - د لالة الفعل على الحدث . ب- دلالة الفعل على الزمن.

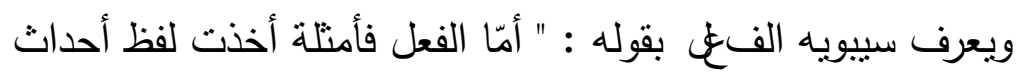

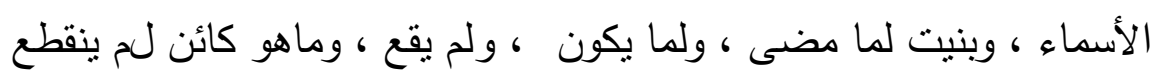

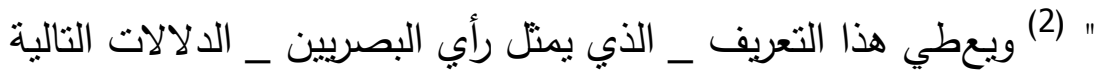

بشأن الفعل :

1 - أنّ الفعل مأخوذ من المصدر ، وقد ظهر من كلام سيبويه أنّ مراده

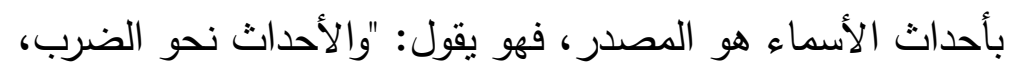

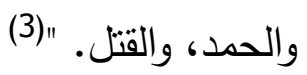

2 - دلالة الفعل على الحدث ، حيث انشترك الفعل مع مصدره في مادة

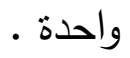

3 - دلاة الفعل على الزمن ، وينقسم الفعل باعتب ارد الزمن إلى: ماضِِ

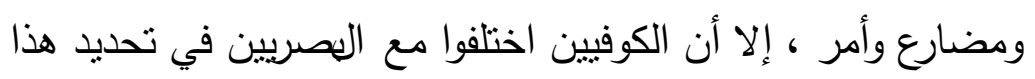


الزمن ، فأبعدوا الأمر ولم يجعلوه قسيماً للماضي والمستقبل ، يظهر

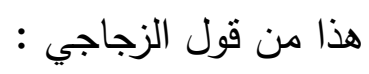

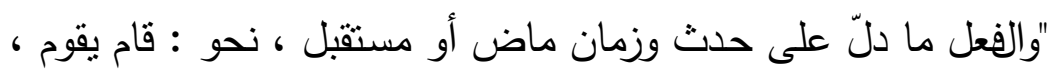

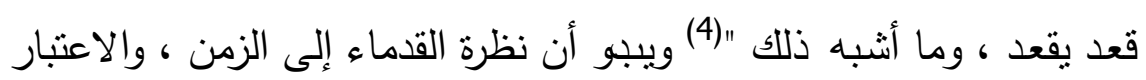

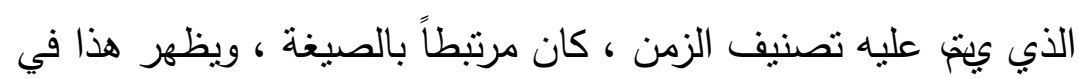

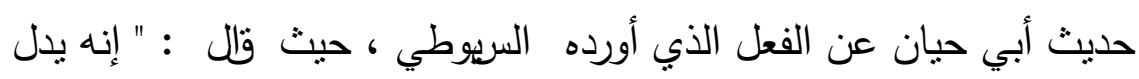

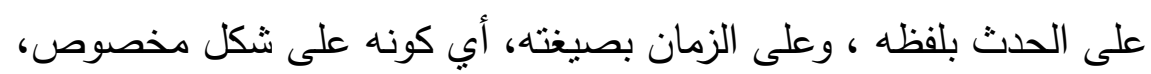

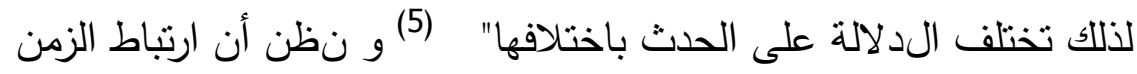

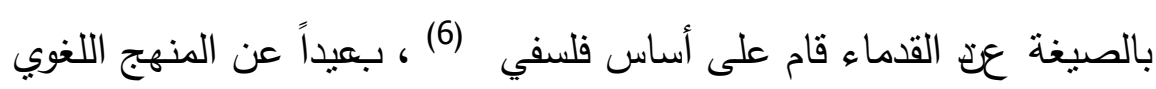

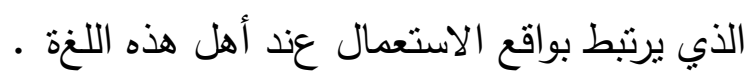

نخلص من هذا إلى أنَّ أهل اللغة من القدماء اتفقوا على أن الفعل يدل

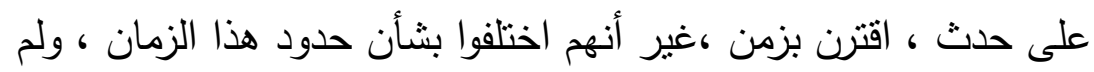

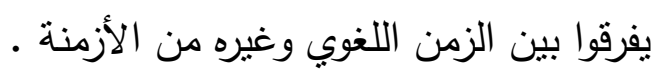
- م الدلالة الزمنية للفعل الماضي في القرآن :

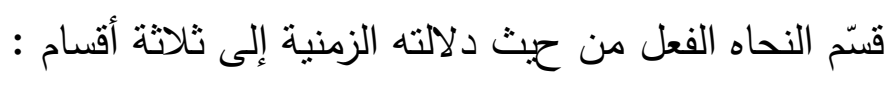

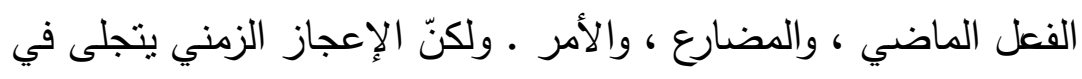

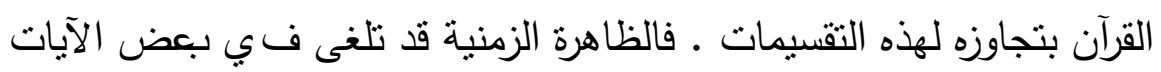

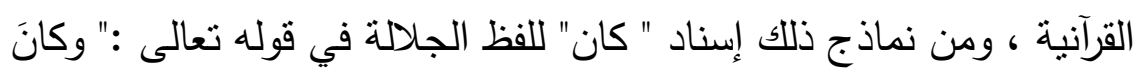

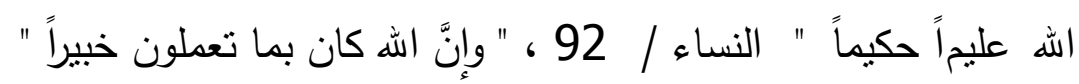

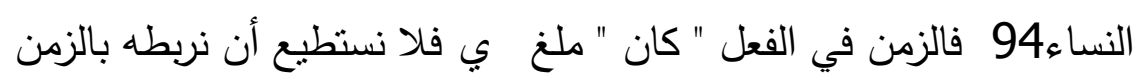

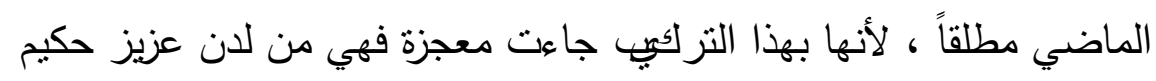

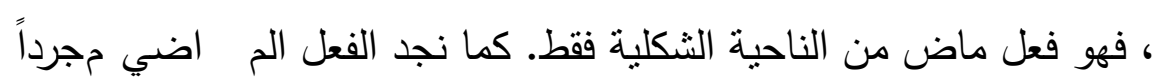




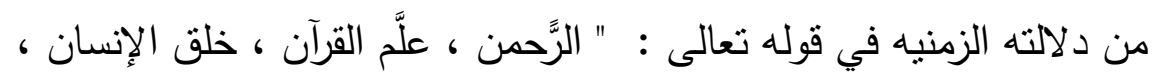

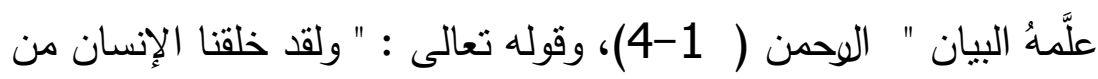

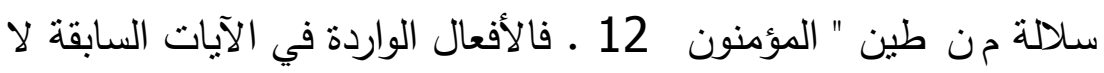

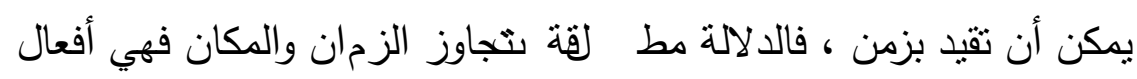

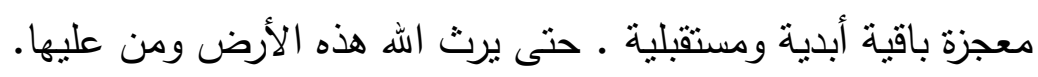
المستقل في صورة الماضي : نجد في القرآن الكريم آياتٍ كثيرةً

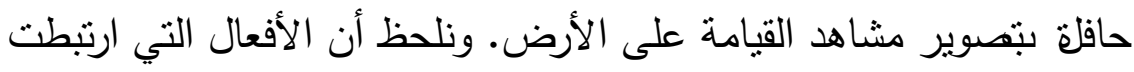

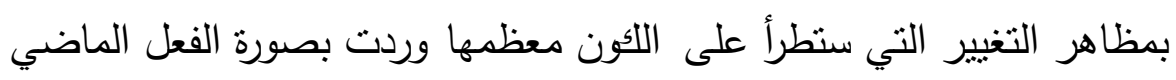

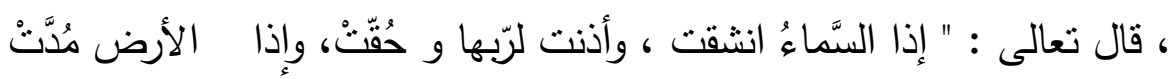

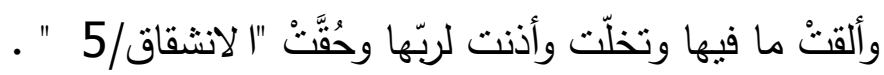
فقمة الإعجاز تتجلى في هذا الاستخدام ، فالأفعال في الآيات

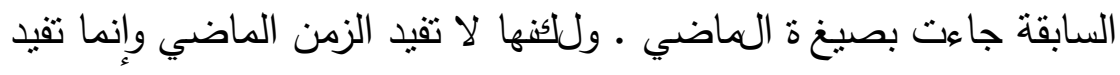

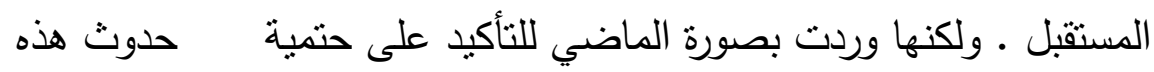

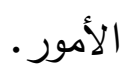

فهي - حتشاً - واقعة لا مفرَ منها ـ كما نلحظظ أنَّ الأفعال الماضية

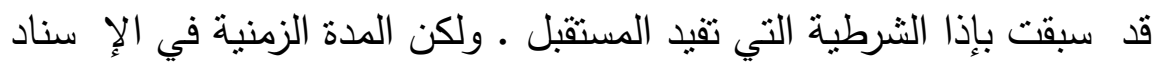

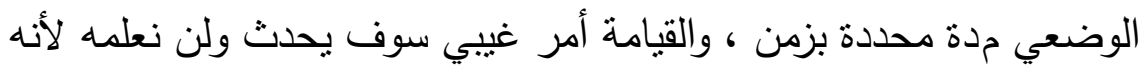

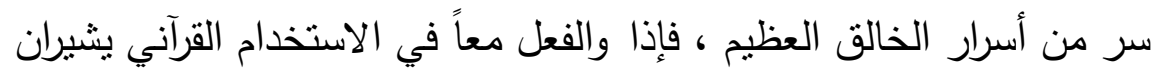

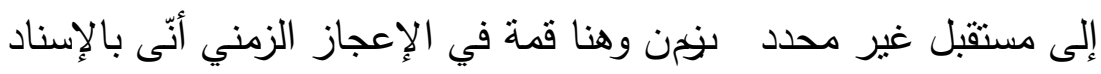
الوضعي أن يصل إلى ذلك ـ (7)

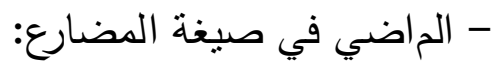




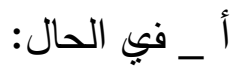

ففي قوله تعالى " وجاء من أقصى المدينة رجلٌ يسعى " يس / 20 ، وقوله جلّ ذكره " فخرج منها خائفاً يترقَّب قال ربِّ نجني من القوم الظالمين " القصص /21، فهاتان الآيتان نجدهما تتصدران بفعلين ماضيين

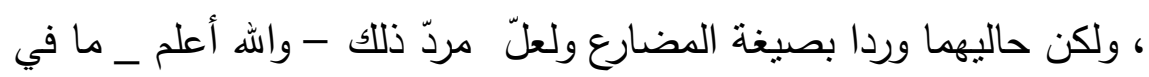
المضارع من قوة على تجسيد الحالة ـ فقي الآية الأولى نجد صورة المؤمن القادم ماتلة أمام أعيننا وهو حريص على حياة رسول اله موسى عليه السلام • وما أبرز من صورة الحالة أنها كانت مصوغة بالفعل المضارع، وكذلك نجد هذا التجسيد في التعبيو بصيغة المضلارع (يترقب ) في الآية الثانية التي أبرزت لنا الحالة النفسية لسيدنا موسى عند خروجه خائفاً.

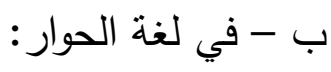

قال الهه تعالى : " إذْ قال إبراهيم ربّي الذي يُحْيَى ويُمْيْتُ ، قال أنا

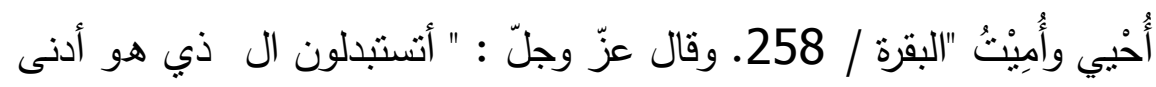
بالذي هو خيرُ "البقرة / 161. وقال تعالى: " وإذا قيل لهم آمنوا بما أنزل الله

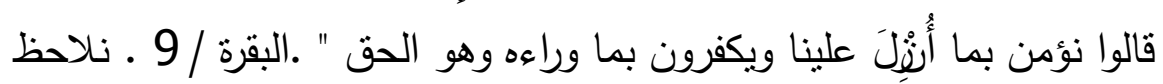
أن الأفعال في الآيات وردت بصيغة المضارع ( يحيى ، يميت ، تستبدلون ، نؤمن ، يكفرون ) ولعلّ ما سوّغ استعمال صريغة المضارع هي لغة الحوار

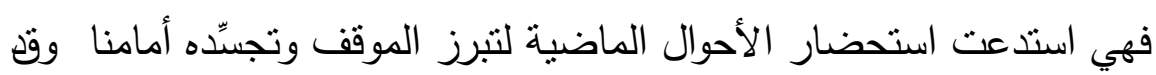
عبّر عنها القدماء بقولهم حكاية حال ماضية . 
في قفله تعالى: "كلاً بل رانَ على قلوبهم ما كانوا يكسبون "الدطفقين

جاء بعد (كان) فعل م ضارع ولم يقل ما كسبوا وذلك ليبين أنّ ما ران على

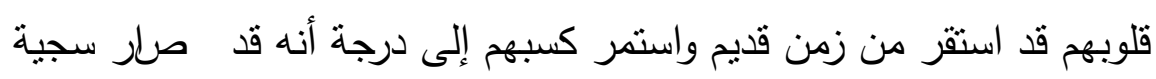
يصعب عليهم الإقلاع عنها.

أفعال الحركة في القرآن الكريم ودلالاته ( الفعل الماضي ) : مفهوم الحركة:

حددت المعجمات العربية دلالة هذه الكلمة بأنها ضد السكون (8)،

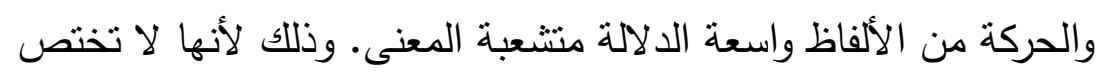

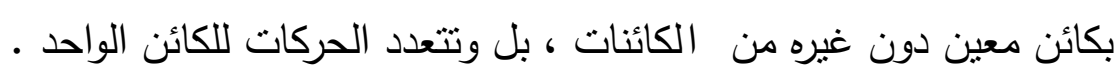

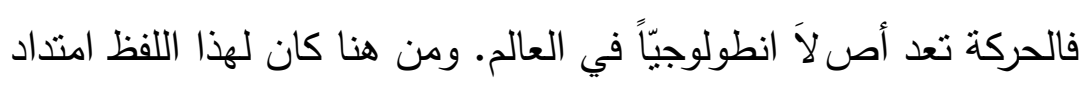

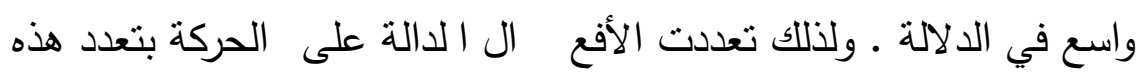

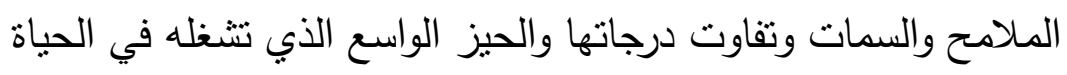
فالحركة هي التعبير الحقيقي عن الحياة ... فالحياة تموج بحركة دائمة

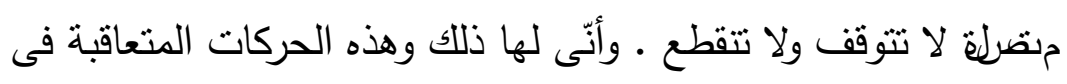

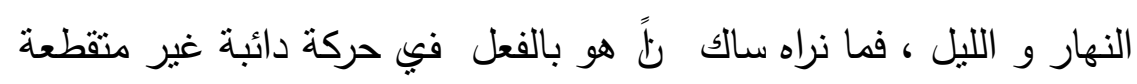

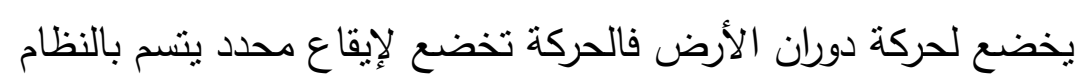

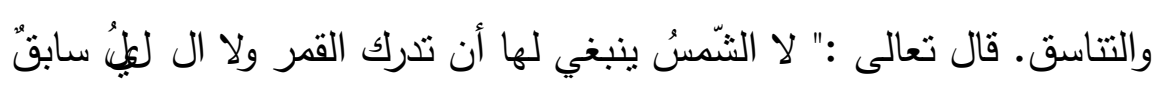

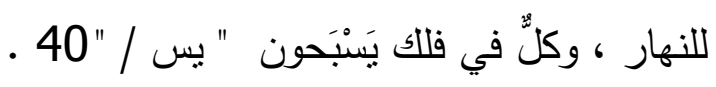
هذه الحركات في المظاهر الطبيعية للك ون تخافقها حركات إنسانية

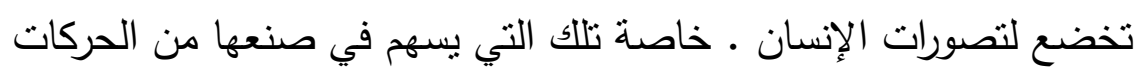
التقنية الهادفة ، أو تلك الحركات العامة التي تكون في إطار المجتمع بأسره

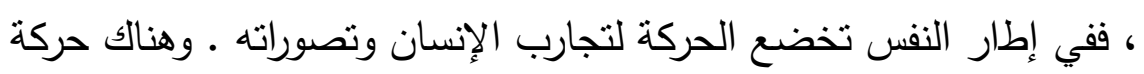


اجتماعية تتمثل في التغييرات ال تي نظرأ على المجتمع وفي الانتقال من مرحلة إلى مرحلة وما يستجد فيها من تبدلات في النظم وفي المعايير الاجتم اعبة وفي الحياة بأكملها.

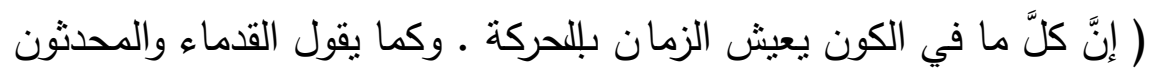
من الفلكيين إنَّ الزمان هو مقدار حركة الفلك ، فالزم ان على ذلى للك هو مقدار

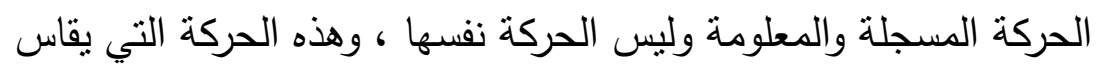
بها الزمان هي حرك ة الكواكب منل الأرض والثمس والقمر وحركات

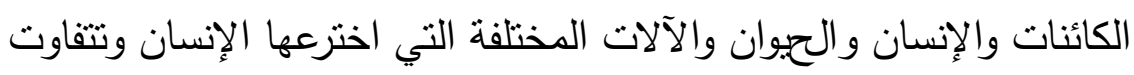

في سرعتها وحركتها " (9).

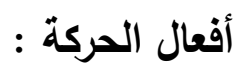
الفعل يأخذ مكاناً هاماً في اللغة لأهمية تأثيره في التعبير عن

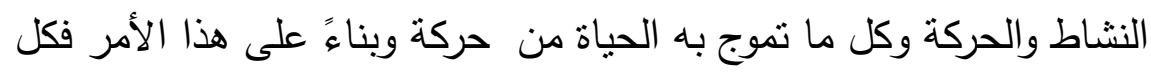

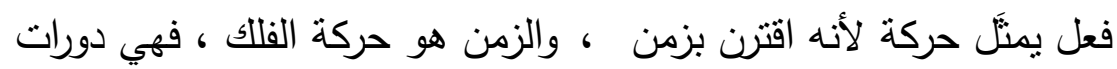

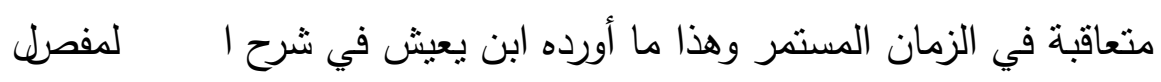

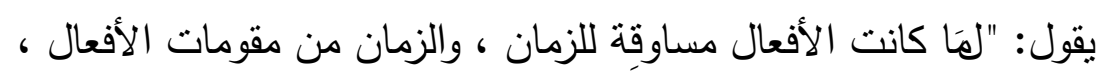

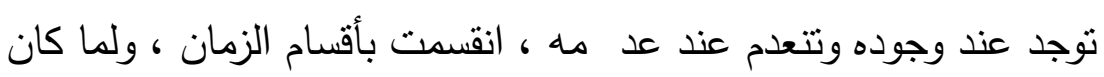

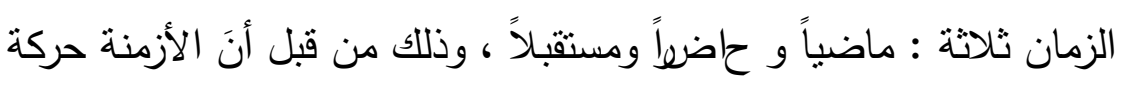
الفللك. فمنها حركة مضت ، ومنها حركة لم تأت ، ومنها حركة تفهل بين

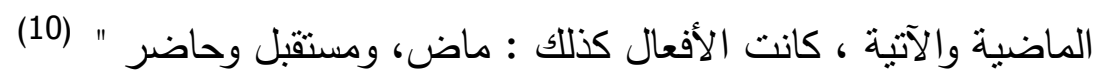

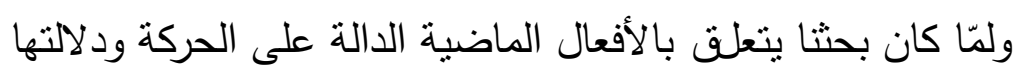

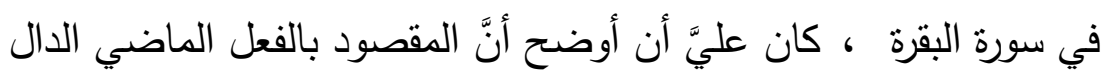


على الحركة هو الفعل الذي أحدث حركة حس ية يمكن إدراكها بوسائل الإدراك الحسية من سمع وبصر ولمس. ويحمل الفعل المعبر عن هذا النوع من الحركة سمات دلالية حركية لها حضور قوي يحتم ترشيح الكلمة للاخول في حيّز مجال ألفاظ الحركة ، (11) وسنجد في سورة البقرة أفعالاً تدل على الحركة ولكنها قد اختقت وراء ظلالات كثيفة ، وسنحاول في هذا البحث حصر أفعال الحركة الماضية ، ونستكثف دلالة الأفعال من خلال موضعها في السياق القرآني ذَهَبَ : - يقع الفعل ( ذهب ) في مجال الحركات الانتقالية الدالة على الذهاب والمضي ، ويدور استعمال مادة هذا الفعل في القديم حول معنى مطلق السيز والمرور ، جاء في اللسان : ( الذهاب : السير والمرور

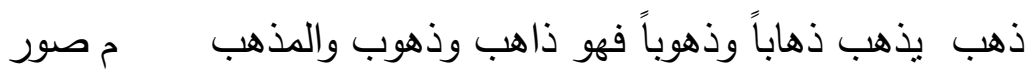
كالذهاب ) (12). عدد المرات التي ورد فيها الفعل : ورد الفعل خمساً وثثلاثين مرة ، إحدى عشرة مرة ماضياً ، واثثتي عشرة مضارعاً ، وانتتي عشرة أمراً.

وورد من الصور الصرفية لهذا الفعل في السياقات القرآنية موضوع البحث " ذهبَ ، ذهبنَا ، ذهَبُو ) ، وفيما يلي عرض لأهم دلالات تللك الصور من هن

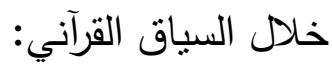

( 1 ) - دلا لة السير والمضي من موضع لآخر، وتظهر هذه الدلالة في السياق الآتي: - n - n

( أ ) - "ثم ذهبَ إلى أهلِه يتمطى " القيامة 33. 
(ب) - "قالوا يا أبانا إنبّا ذَهَبْنَا نستنِقُ وتركنا يُوْسُفَ عِنْدَ متاعنا فأكله

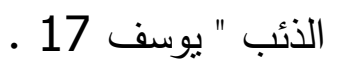

( 2 ) - دلالة السير والمضي مع إفادة الصحبة ( تخصيص الدلالة ) كما

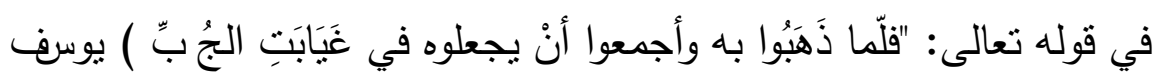

فتعدية الفعل ( ذَهَبَ ) بالباء دون الههزة حمل معنى الاصطحاب ، فقد اصطحبوا يوسف معهم على نية الغدر به .

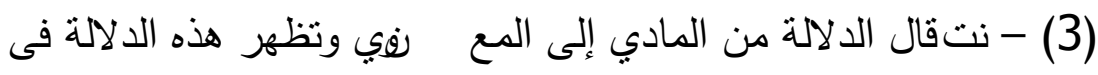

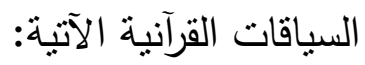

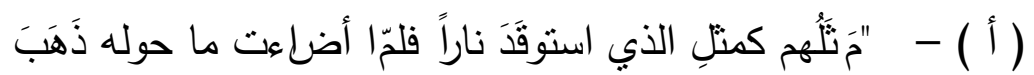

\section{اللهُ بنورهم" البقرة 17}

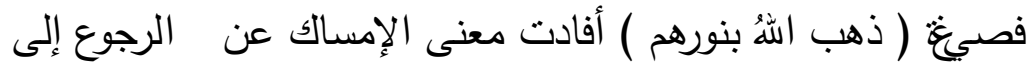
الحالة الأولى التي كان المنافقون عليها منتفعين بفيجيء الإسلام

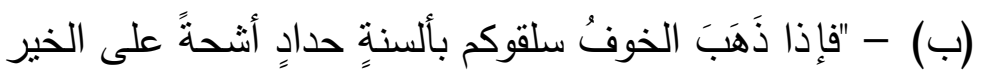

$$
\text { "الأحزاب أب أب } 19 .
$$

(ج) - " "وله شَاء الله لَذَهَبَ بِنَمْعِهم و أبصارهم " البقرة 20 . يلاحظ أن صيغة ( ذهب ) في الآيتين السا بقتين حملت معنى الإزالة.

4 - انتقال الدلالة من الكل إلى الجزء ويظهر ذلك في قوله تعالى: "ما

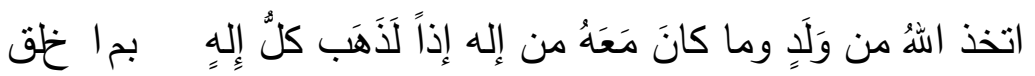
ولعلا بعضهم على بعضٍ " المؤمنون/ 91. يلاحظ أن الفعل ذهب حمل معنى انفرد . 


\section{مشى:}

تفيد المعجمات أن دلالة الفعل (مشى ) تدور حول معنى الانتقال

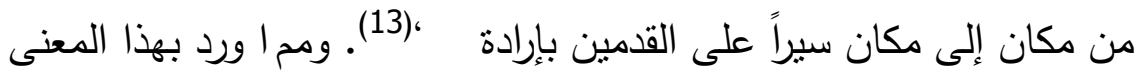

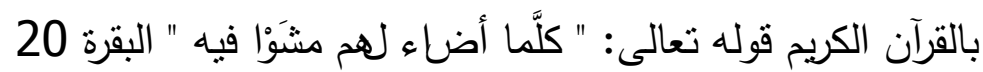

عدد المرات التي ورد فيها الفعل :

ورد الفعل إحدى وعثرين مرة ، مرةً م م اضياً ، وثماني عشرة مرة

مضارعاً ومرتين أمراً.

وفيما يلي عرض لالالة الفعل الماضي من خلال السياق القرآني .

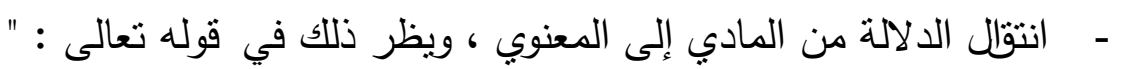

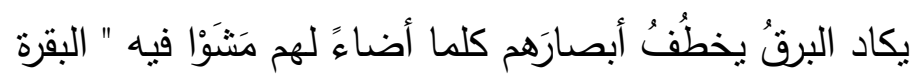

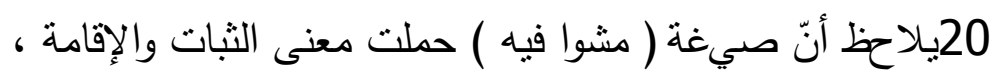

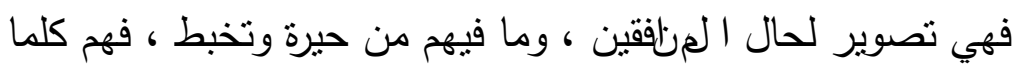

رأوا في الإيمان ما يعجبهم ثبتوا عليه وأقاموا فيه.

- حددت المعمات العربية في القديم الدلالة الحركية للفعل ( قام ) ،

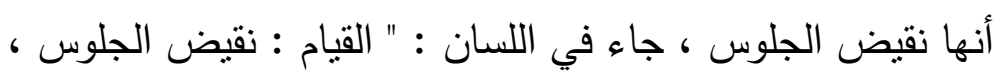

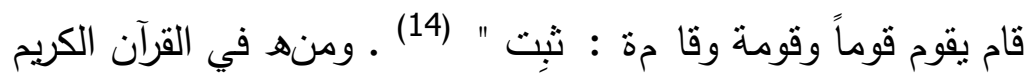
قول اله تعالى:" و إذا أظلم عليهم قاموا " البقرة / 20

عدد المرات التي ورد فيها الفعل :

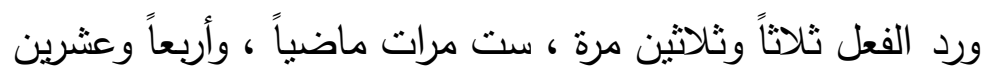

مرة مضارعاً ، ثلاث مرات أمراً.

وورد من الصور الصرفيه لهذا الفعل في مات السياقات القرآنية موضوع البحث

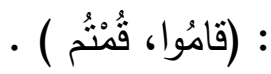


وفيه يلي عرض لمعاني تلك الصور من خلال السياقات الآتية :

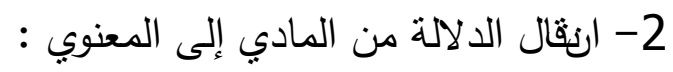
حمل الفعل ( قاموا ) في قوله تعالى :" وإذا أظلمَ عليهم قامُوا " البقرة 20. معنى ثنتوا على ضلالهم ونفاقهم.

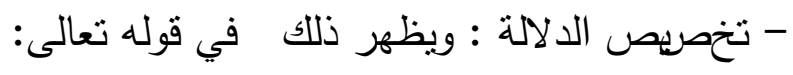

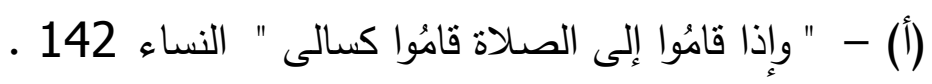

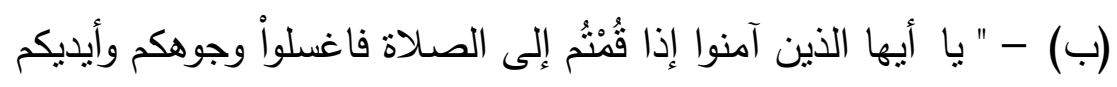
إلى المرافق " المائدة 6. فصيع الفعل ( قام ) حملت في الآيتين السابقتين معنى المبادة إلى الصلاة

$$
\text { 3- تأرجح الدلالة بين المادي والمعنوي : }
$$

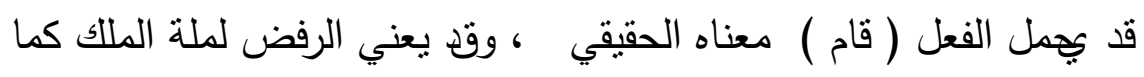

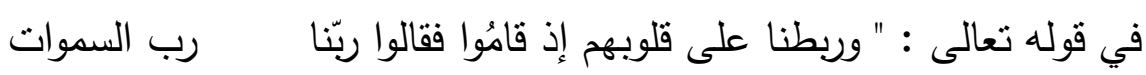

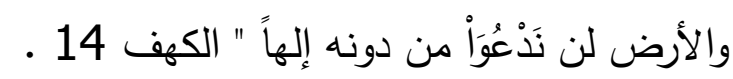

و يرد الفعل ( سجد ) ضمن أفعال الحركة التي تنتهي إلى ثبات

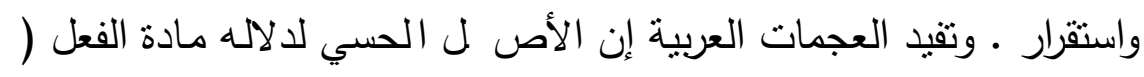

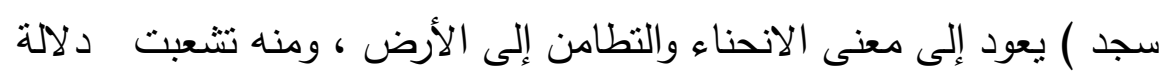

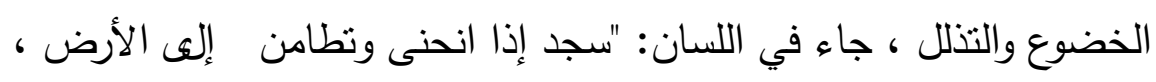

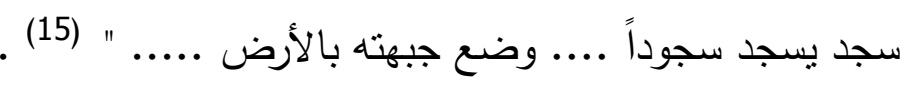

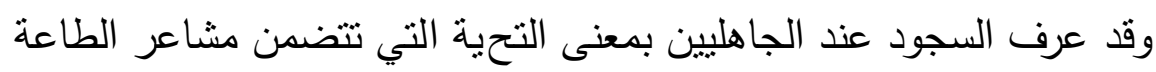
والولاء ، قال الأعشى : فلم| أثانا بعيد اللكرى سجدنا ورفعنا عمارا ـ (16) 


$$
\text { - عدد المرات التي ورد فيها الفعل : }
$$

ورد الفعل ستاً وثلاثين مرة ، موزّعاً بين الماضي والمضارع والأمر، فقد جاء ماضياً ثماني مرات ، ومضارعاً ست عشرة مرة ، وأمراً اثثتي عشرة مرة. ويمكن ملاحظة الدلالة الحركية للفعل الماضي ( سجد ) من خلا السياقين التاليين :

- حمل الفعل ( فسجدوا ) في قولهُتعالى :" وإذ قُلْنَا للملائكة اسجُدوا لآدم فَسَجَدوا "البقرة 341 معناه الحقيقي ، ويفيد معنى الانصياع

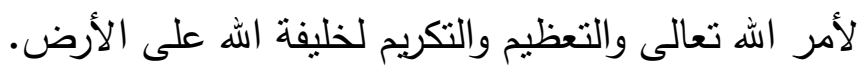
- تخصيص الدلالة حيث انتقلت الدلالهـ من العام إلى الخاص:

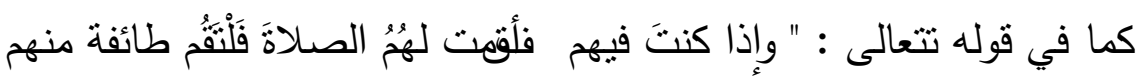
معك وليأخذوا أسلحتهم فإذا سَجَدُو فليكونوا من ورائكم " النساء 102 ـ فالفعل " سجدوا " حمل معنى السجود الذي يُوَّدي أثثاء الصلاة ، ولا يكون

$$
\begin{aligned}
& \text { السجود إلا لله تعالى. } \\
& \text { : تَبعَ }
\end{aligned}
$$

يقع الفعل( تَبَعَ ) في مجال الحركة الانتقالية المطلقة ، وحددت المعجمات العربية دلالته الحسية الحركية بمعتى السير في آنز آخر ،جاء في اللسان

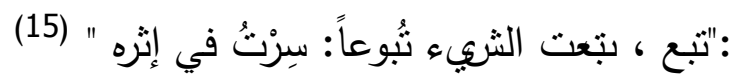
- عدد المرات التي ورد فيها الفعل :

ورد الفعل ( تبع ) تسع مرات ، سبع مرات ماضياً ، ومرتين

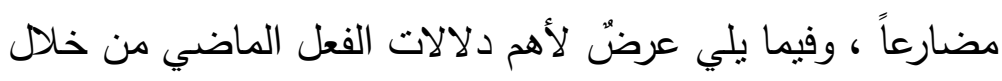
سياقات الآيات القرآنية الآتية : معبية

أ - انتقال الدلالة من المادي إلى المعنوي: ويظهر ذلك في قوله تعالى: 
" فمن تَبْعَ هُدايَ فلا خوفَ عليهم " البقرة 38 ، فالفعل ( تبع ) حمل معنى اهتدى بيياني الذي أنتيته على ألسنة رسلي.

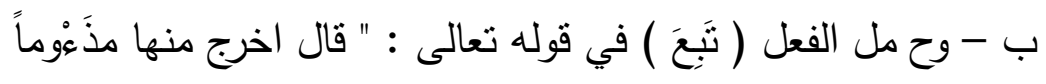

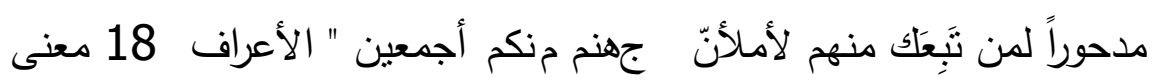

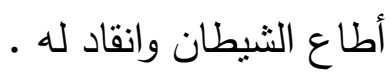

3- تخصيص الدلالة : وظهر هذا ا لمعنى في السياق الآتي ، حيث حمل لهل

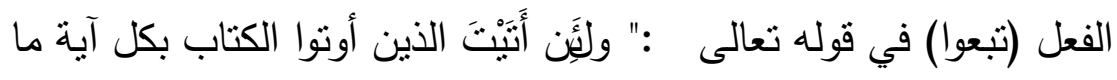

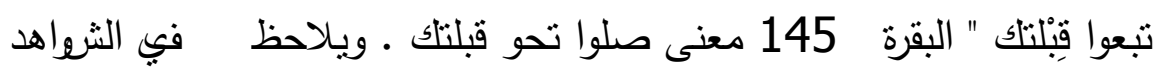

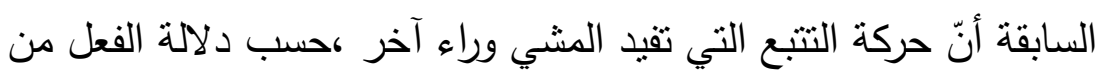

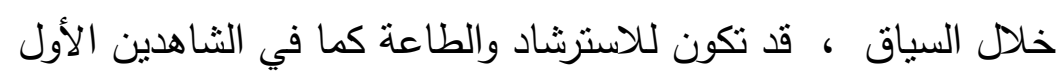

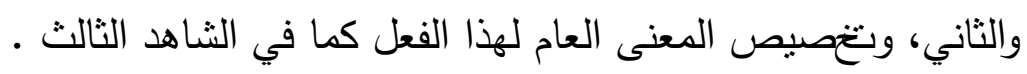

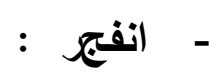

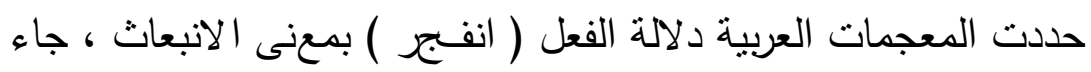

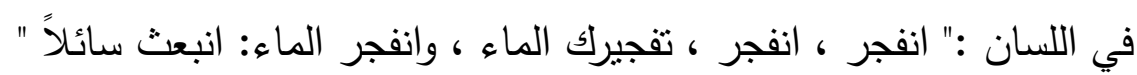

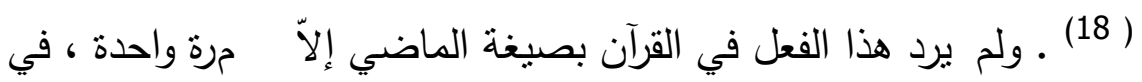

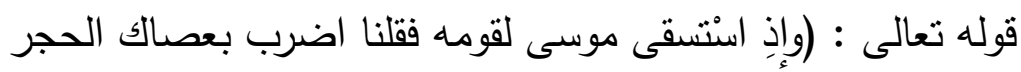

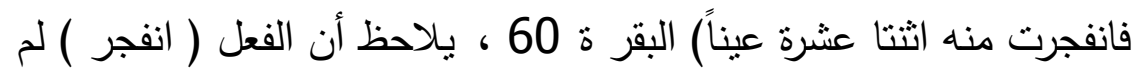

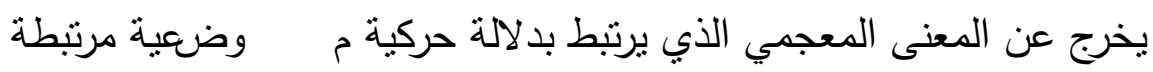

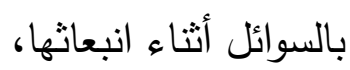
ضَرَبَ : nَبَ

سجلت المعمات في القديم المعنى الحركي الحسي للفعل ( ضرب ) ،

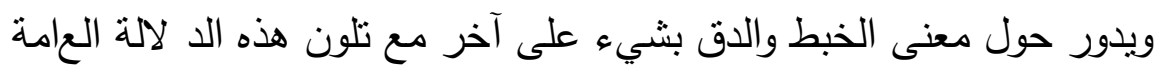


حسب السياق الذي ترد فيه ، جاء في اللسان :" الضرب معروف ، وضرب

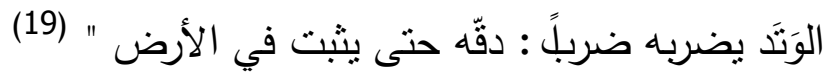
عدد المرات التي ورد فيها الفعل : ورد الفحل ( ضرب ) خمساً وخمسين مرة ، ثمانياً وعشرين مرة

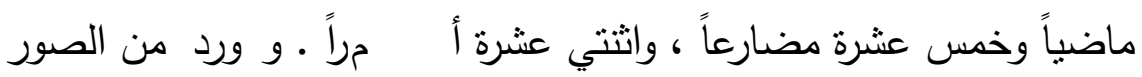
الصرفيه لهذا الفعل في الآيات القرآنية موضوع الدراسة:

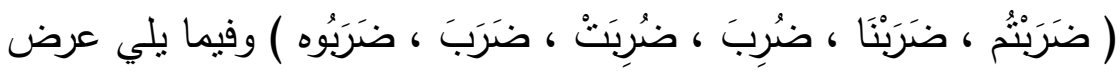
لأهم معاني تلأك الصور من خلال السياقات الآتيه : 1- تخصريص الدلاله : كما في قوله تعالى :

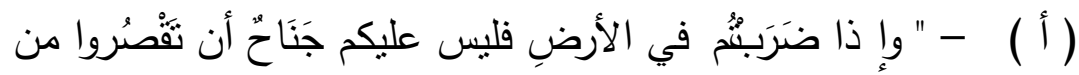

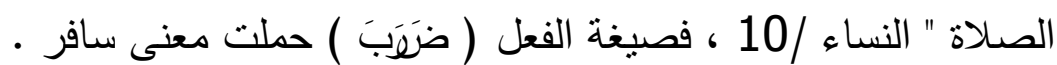

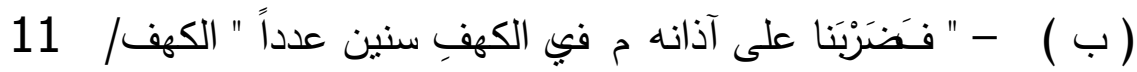
فصيغة الفعل (ضَرَبْنَا ) حملت معنى أنمناهم إنامة طويلة الأمد ،

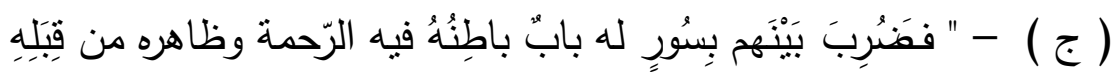

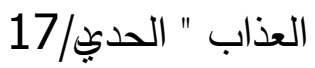
فالفعل ( ضُربَ ) حمل معنى فُصِلَ. 2- انثال الدلالة من المادي إلى المعنوي:ويظهر ذللك في السياقين الآتيين:

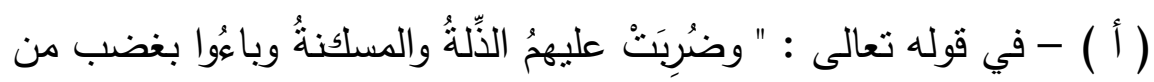

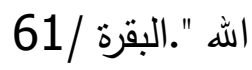

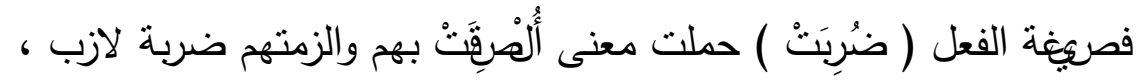

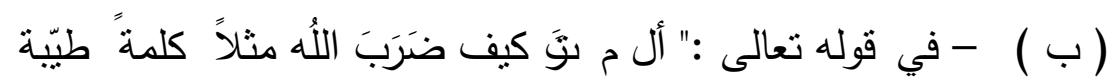
كثجرة طيّبة أصلها ثابت وفَرْعُها في السماء : إبراهيم /24. فصيق الفعل ( ضَرَبَ ) حملت معنى بيّن ووضتح عن طريق الأمثال. 


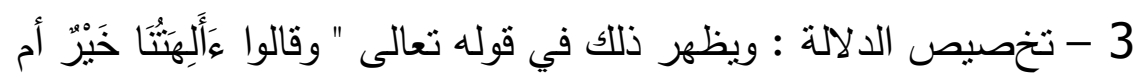

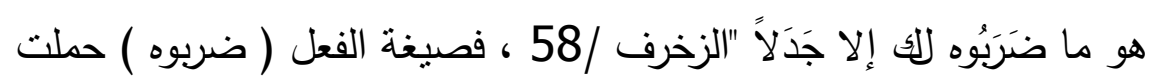
معنى منلوا أو قالوا.

رفع : مغنى

يقع الفعل رَفَعَ في م جالات الحركات التي تأخذ فيها ملمح الاتجاه دوراً

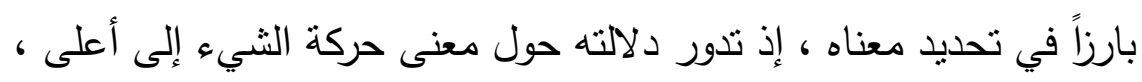

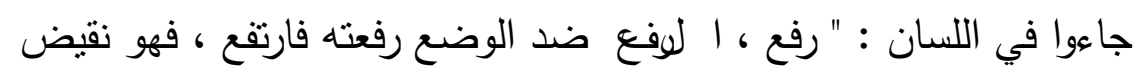
الخفض في كل شيء " (20)

عدد المرات التي ورد فيها الفعل :

ورد الفعل اثثتين وعشرين مرة ، خمس عشرة مرة ماضياً ، وسبع مرات الفرل

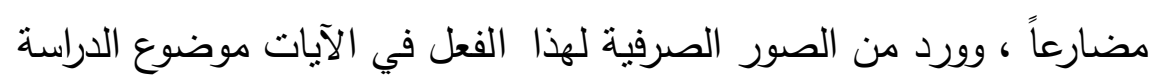

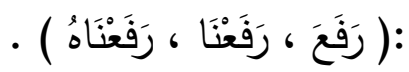

وفيج يلي عرض لأهم معاني تلك الصور من خلال سياقات الآيات القرآنية التالية:

1 - دلالة حركة الشيء إلى أعلى ( المعنى العام ) وتظهر هذه الدلالة

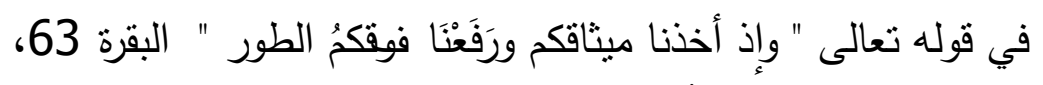

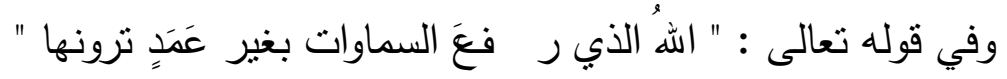

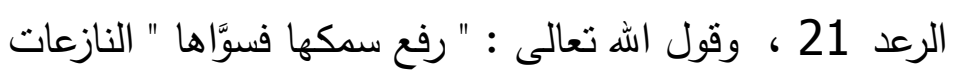

28/

2 - انقال الدلالة من العادي إلى المعنوي :

سجلت العربية قدراً كبيراً للفعل ( رفع ) في مجال الدالالات الدال الدجازية

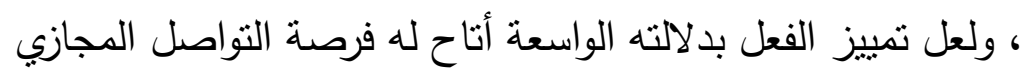


مع مجالات دلالية أخرى كثيرة غير مجال الحركة، وسوف أورد هنا

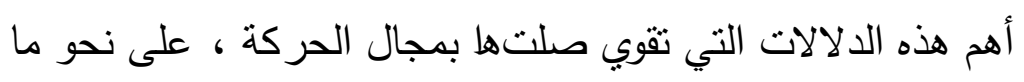
يظهر من الثواهد القرآنية الآثية :

أ - دلا لة ارتفاع الثأن والم كانة الاجتماعية أو المكانة الدينية للإنسان هو لون من الارتقلع المعنوي ، كما يظهر من الآية القرآنية الآتية :

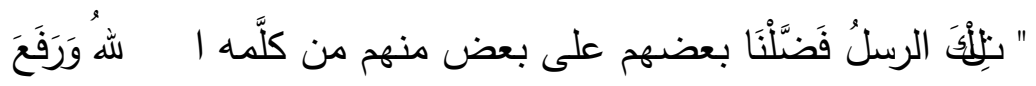
بَعْضَهُهُ درجاتٍ " البقرة /253.

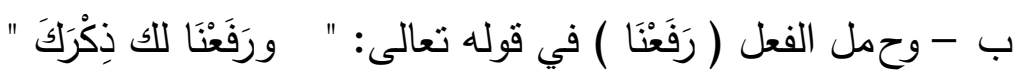

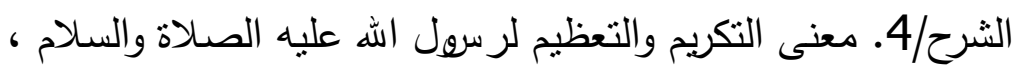

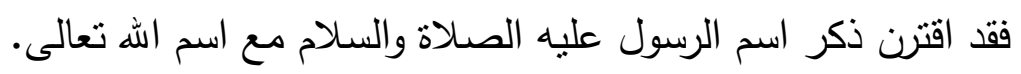

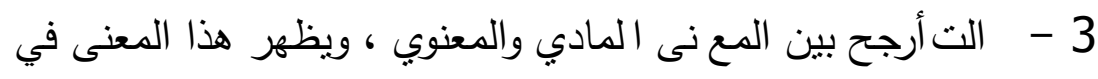

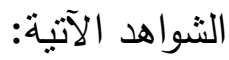

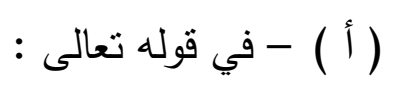

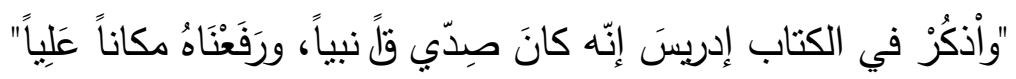

$$
\text { مريم /57/56. }
$$

حمل الفعل ( رفعناه ) معناه الحقيقي ، فقد قي ل رفع سيدنا إدريس

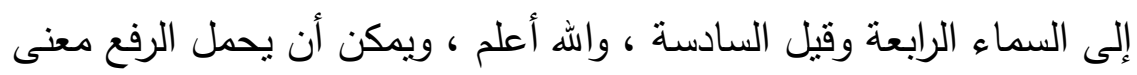

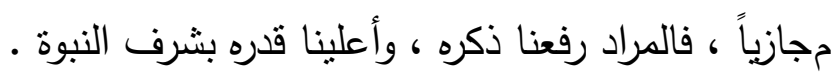

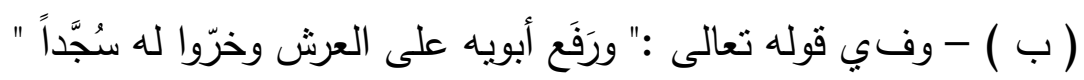
يوسف/100 ـ يمكن أن يكون معنى ( رفع ) ي فيه التعظيم و التلكويم لدكانة

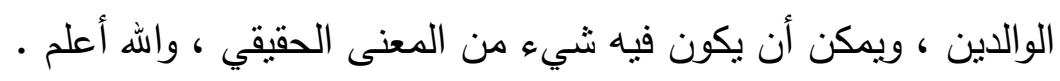


سجلت المجمات العربية الدلالة الحركية الانتقالية الدالة على

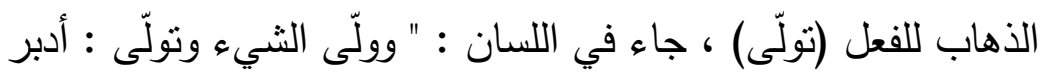

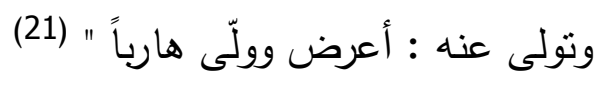
عدد المرات التي ورد فيها الفعل:

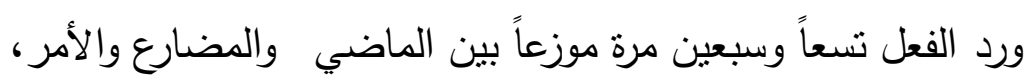

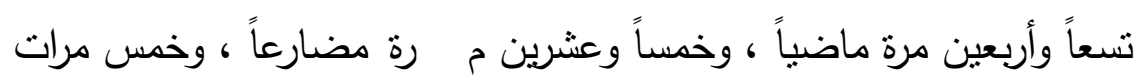

أمراً.

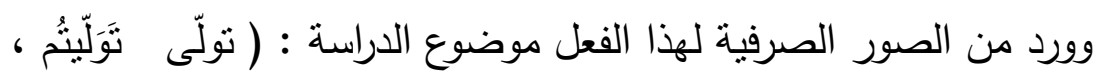

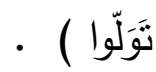

وفيما يلي عرض لأهم معاني تلك الصور من خلال سياقات الآيات القرآنية

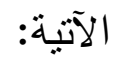

1 - الثٔوجح بين المعنى المادي والمعنوي ـويظهر هذا في قوله تعالى:

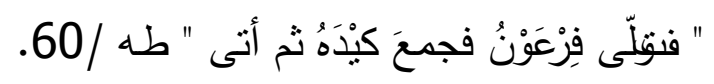

فالفعل ( تولّى ) قد يحمل معناه الحقيقي ، وقد يحمل معنى التكبر

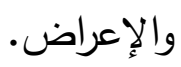

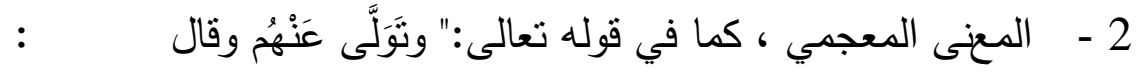

$$
\text { يُأسفي' على يوسف " يوسف /84. }
$$

3 - تخصيك الدلالة: ويظهر هذا المعنى في السياقات القرآنية الآتية:

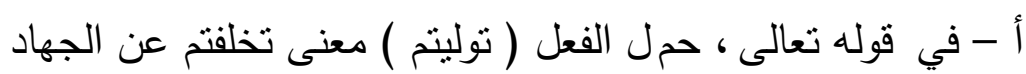

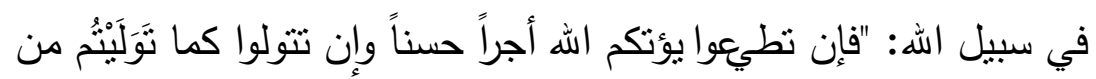

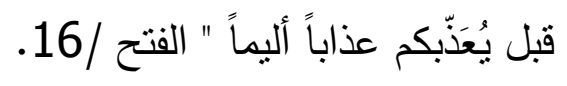


ب - وحمل الفعل ( تولوا ) معنى اتغذوا اليهود أصدقاء ، في قوله تعالى :" ألم تر إلى الذين تولوا قوماً غضب الهُ علئ اليهم ما هم منكم ولا منهم " المجادلة /14 ج - وفي قوله تعالى :" ومن يثاقق الرسول من بعد ما تبين له الهدى

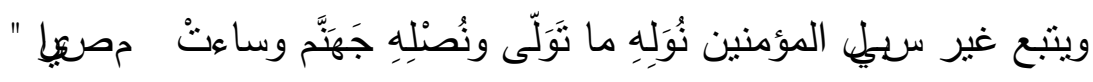

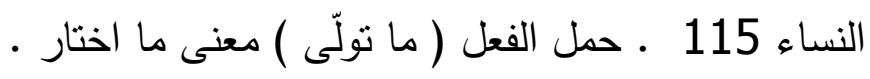

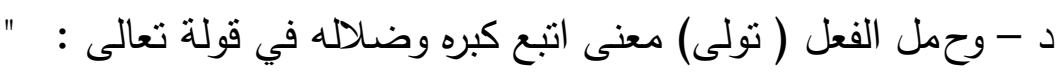

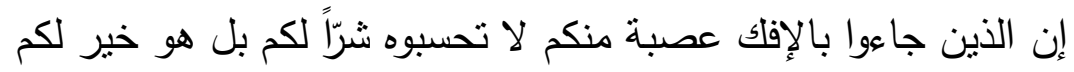

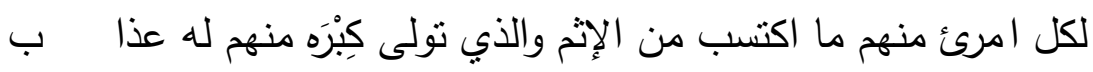
عظيم " النور/11

4 - انتقال الدلالة من المادي إلى المعنوي : ويظهر هذا المعنى في

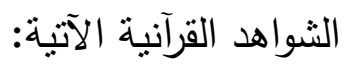

أ - حمل الفعل ( تو لَّى ) معنى استتكف في قوله تعالى :" فَأَعْرِ الَّل

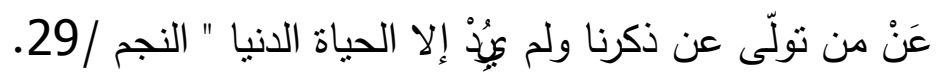

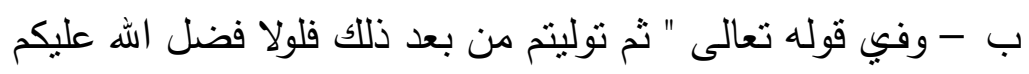

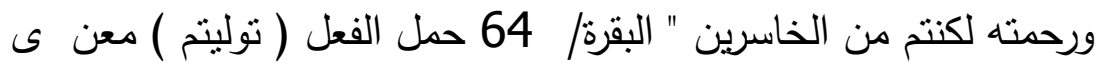

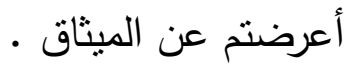

ج - وفي قوله تعالى :" فإن توليتم فما سألتكم من أجر إن أَجْرِيَ إلا ألا

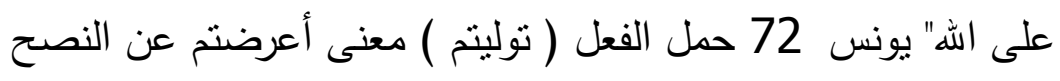

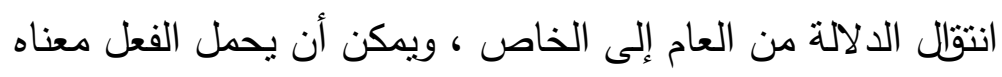

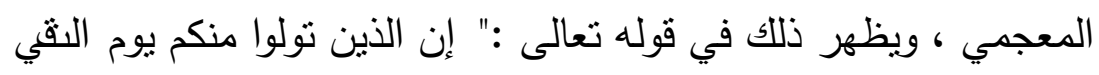
الجمعان إنما استزلهم الثنيطان ببعض ما كسبوا " آل عمران / 155 فالفعل ( تولوا ) خمل معنى انهزموا. 
تدور دلالة الفعل (جاء) في المعجمات حول معنى الإتيان ، جاء في

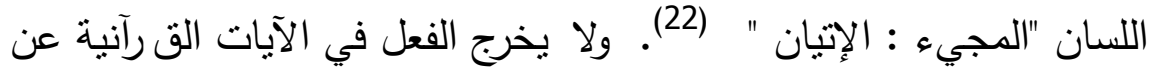
دلالته المعجمية ، إذ تقيد سياقات الآيات القرآنية أن أفعال هذه المادة تدور حول معنى الإتيان والحضور ، وإن المجيء من الحركات الانتقالية الدالة على الإياب ، ويسند المجيء في الأعم الأغلب للإنسان. - - عدد المرات التي ورد فيها الفعل :

- ورد الفعل في مائتين وثمان وسبعين آية وكلها و اردة على صيغة الماضي ، ونجد من الصورة الصرفية لهذا الفعل في الآي ات القرآنية موضوع البحث : " جاء ، جئت ، جاءوا " ، وفد تفاوت ت دلالاته

بحسب وروده في السياق القرآني، وفيما يلي عرض لأهم دلالات الفعل في السياقات القرآنية موضوع البحث:

1 - الهعنى العام : الإتيان والحضور ، ويظهر ذلك في الآيات الآتية: ( أ ) - وإن كنتم مرضى أو على سفر أو جاء أحد منكم من الغائط أو الو لامستم النساء فلم تجدوا ماءً فتيمموا صعيداً طيباً " النساء / 43

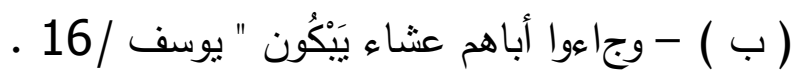
( ) ) - وجاء السَّحَرَةُ فِرْعَونَ قالوا إِنّ لنا لأجراً إن كنا نحن الغالبين "الأعراف / أن (113. ( ) - " فلبثت سنين في أهل مدين ثم جئت على قدر يا موسى "

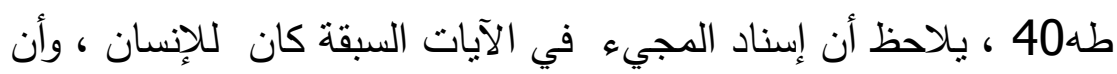
صيغ الفعل ( جاء ) الصرفيه حملت المعنى المعجمي • 3 - تأرجح الدلالة بين المادي والم عنوي ويظهر ذلك في الآيات القرآنية 


$$
\text { ( أ ) - " قالوا الآن جئت بالحق " البقرة / } 71
$$

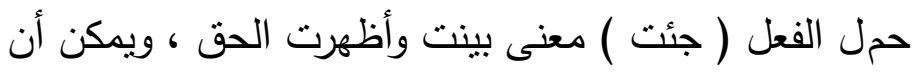

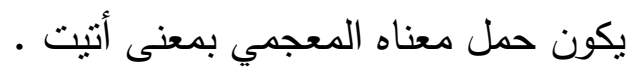

$$
\text { (ب ) - "وجاء ربك والملك صفاً صفاً " الفجر / } 22 \text {. }
$$

تعددت دلالات لفع ل ( جا ء ) ، وذللك لأن المجيء يستدعي الحركة

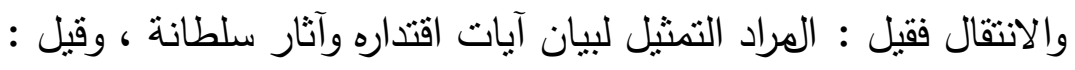

$$
\text { مجيء أمره وقضائه ، وظهور آياته . }
$$

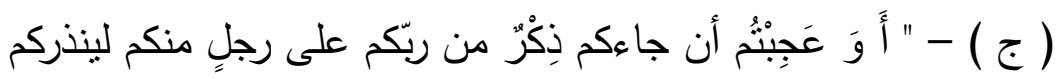

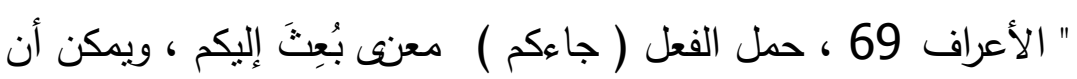

$$
\text { يكون بمعنى أنى . }
$$

3 - انتقال الدلالة من المادي إلى المعنوي ويظهر ذلك في الثواهد

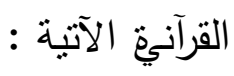

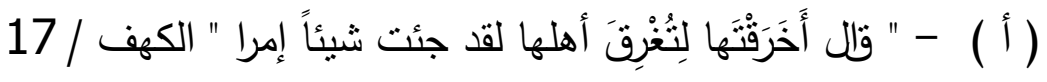

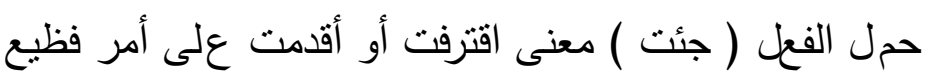

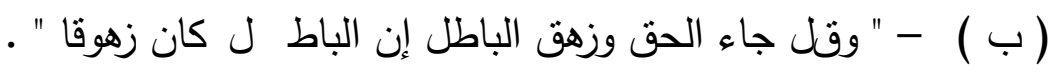

$$
\text { الإنراء / }
$$

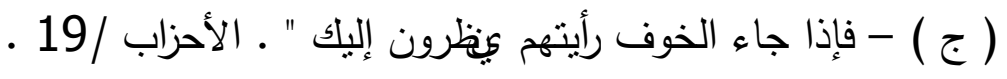

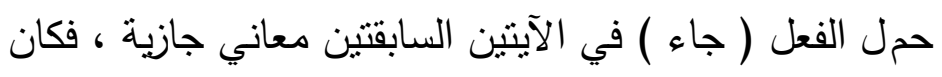

التثخيص للكلى من الحق والخوف .

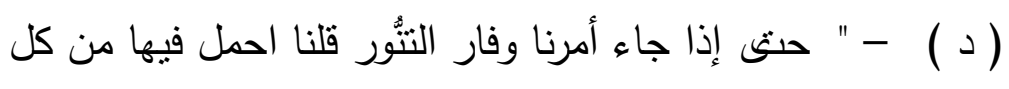

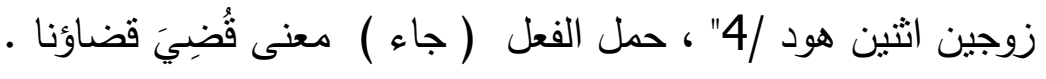

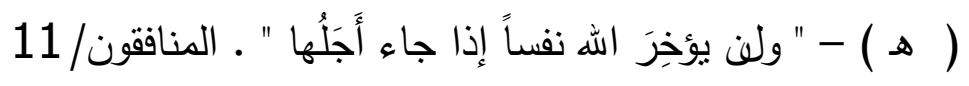


حمل الفعل ( جاء ) معنى حضر أجلها وانقضى عمرها . 4 - تخصيص الدلالة : كما في قوله تعالى : " وجاعوا على قميصه بدةٍ لكذبٍ " بوسف /18.

فالفعل ( جاعوا ) حمل معنى لطخوا قميصه ، وقد يحمل معناه المعجمي بمعنى أتوا على قميصه. فتح :

حدد ت المعجمات العربية دلالة الفعل ( فتح ) أنها نقيض الإغلاق ومنه قوله تعالى " لا تقتّح لله أبواب السماء " الأعراف 40 وتمتد هذه الدلالة للفعل ( فتع ) إلى الآيات القرآنية موضوع البحث ، حيث يرد الفعل في سياقاتها للالالة على حركة تتنهي إلى ثبات واستقرار ، ومن خلال إسناد الفعل ( فتح ) إلى فاعله يمكن تخصيص حركة ال تتح والمقصد منها . عدد المرات التي ورد فيها الفعل : ورد افعل ست عثرة مرة، اثتتي عثرة مرة م اضياً ومرتين مضارعاً ومرتين أمراًً.

ونجد من الصور الصرفيه لهذا الفعل في الآيات القرآنية موضوع البحث: ( فتح ، فتحوا ، فتحنَّا ، فُتِحَتْ ... ) ويظهر استعمال هذه الصور في الدلالات الآتية: 1 - الدلالة الحركية الحسية للفتح :

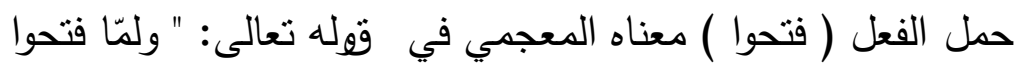

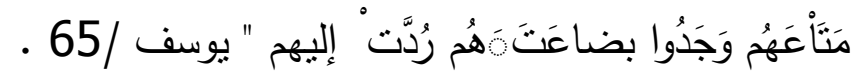

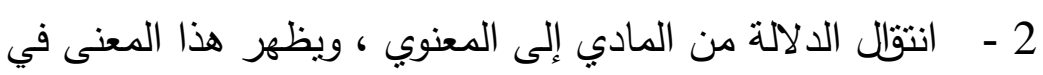

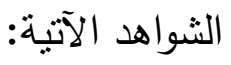




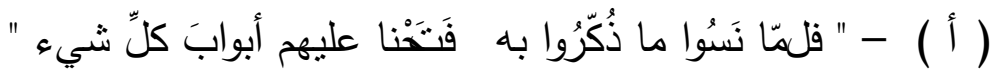
الأنعام 44 ، حمل الفعل ( فتحنا ) معنى وسعنا الرزق.

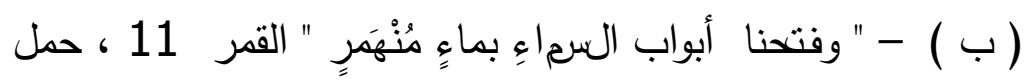

الفعل (فتحنا) معنى مجازياً وهو أرسلنا المطر مِدْراراً .

3 - تخصيص الدلالة:

حجل الفعل ( فتح ) معنى قضى وحكم به عليكم في قوله تعالى : "

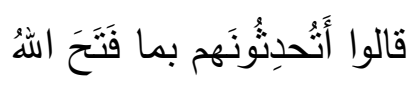

علئكم " البقرة 76 ـ.

4- تأرحج الدلالة بين المعنى الحقبقي والمعنوي ، ويظهر هذا في قوله

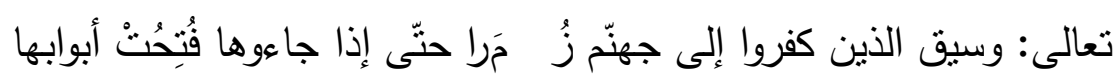

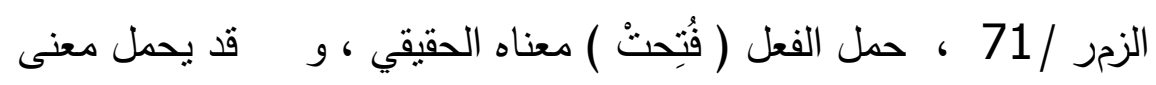
معنوياً ليشير به إلى ما اعدّ للكفار من عذاب ألبه.

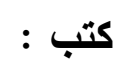

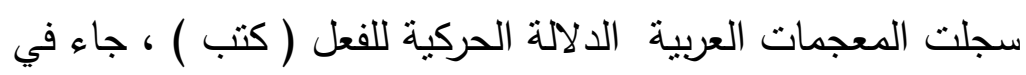

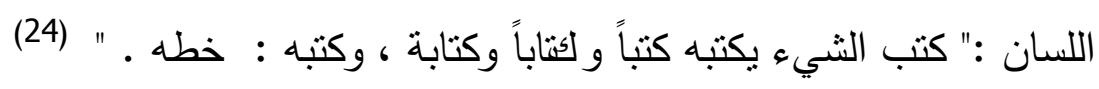

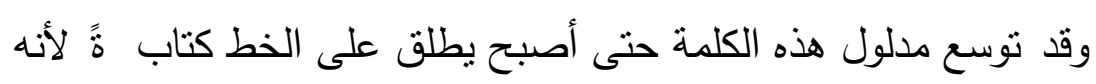

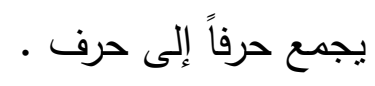

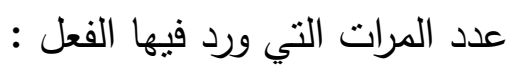

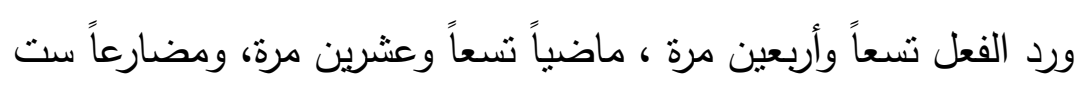

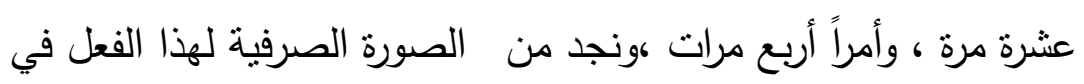

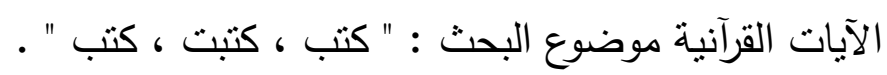

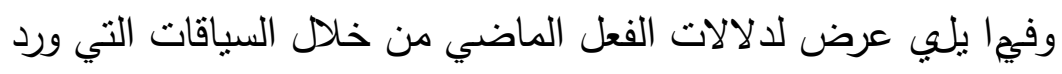

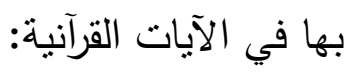


1 - المعنى المعجمي : ويظهر ذلك في قوله تعالى :

" فويل للذين يكتبون الكتاب بأيديهم ثمَّ يقولون هذا من عند الله

ليشتروا به ثمناُ قلبلاً فويلٌ لهم مما كتبت أيديهم " البقرة 79.

2 - تخصيص الدلالة : ويظهر هذا المعنى في الثواهد الآتيه:

( أ ) - " فالآن باشروهن وابتغوا ما كتب الله لكم " البقرة 187

حمل الفعل ( كتب ) معنى م ا قسم الله لكم وأثبت في اللوح.

( ب ) - " كُنِبَ عليكم إذا حضر أحدَكم الموتُ إن ترك خيراً الوصية

للوالدين والأقربين " البقرة 180.

( ج ) - " يا أيها الذين آمنوا كتب عليكم القصاصُ في القتلى " البقرة

.178

يلاحظ أن الفعل ( كتب ) حمل معنى فرض .

( د ) - كنب على نفسه الرحمة " الأنعام / 12

حمل الفعل ( كتب ) معنى فرض ، مع الفرق بين الفرض

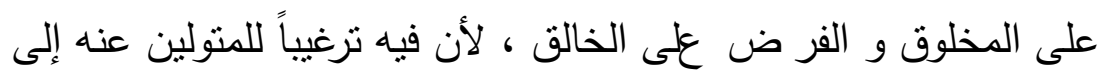
الإقبال إليه لأن رحمته تتجاوز أخطاءهم •

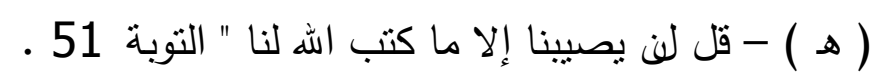

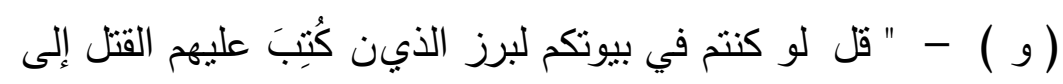

مضاجعهم " آل عمران 154.

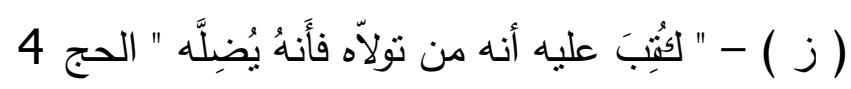

يلاحظ أن الفعل ( كتب ) في الآيات المتقدمة حمل معنى قضى وحكم . تولاه

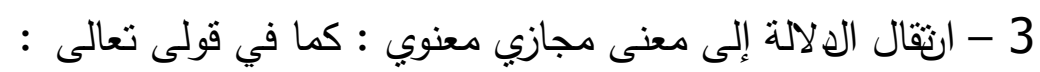

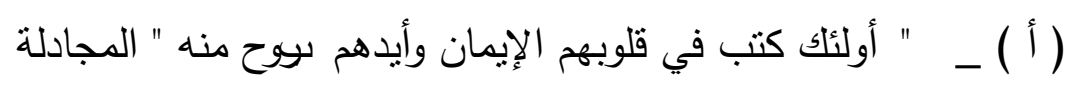


حمل الفعل ( كتب ) معنى جعل .

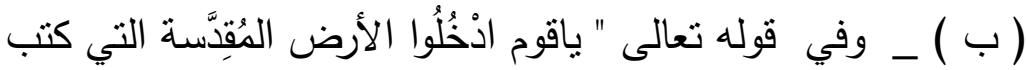

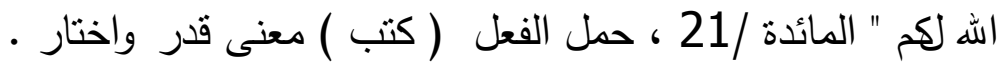
4 - تأرجح الدالة بين المادي والمعنوي : ويظهر ذلائك في قوله تعالى : " ولاينالون

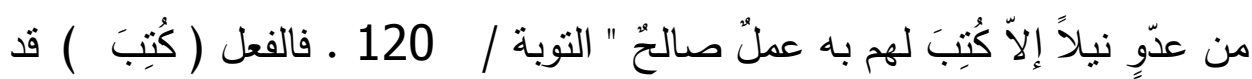

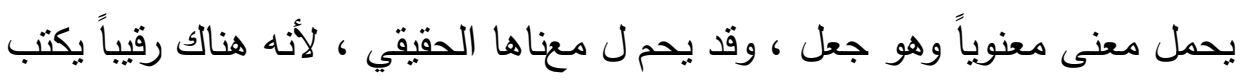

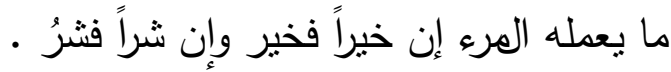

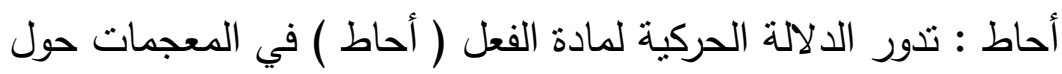

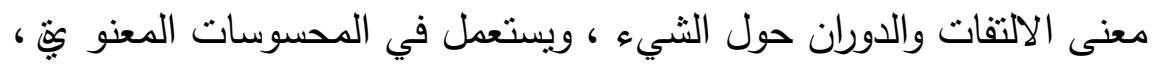

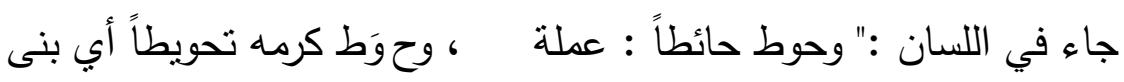

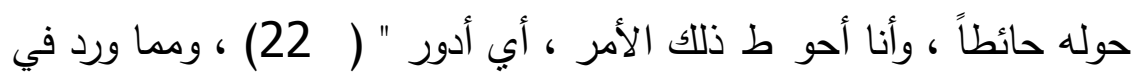
القرآن الكريم بلالة معنوية قول اله تعالى : " وأحيط بثره " الكهف 42 ، 42

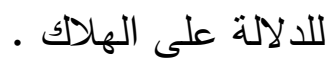
عدد المرات التي ورد فيها الفعل : ورد الفعل سبع عشرة مرة وقد تفاوتت دلالته من آية إلى أخرى ، تبعاً

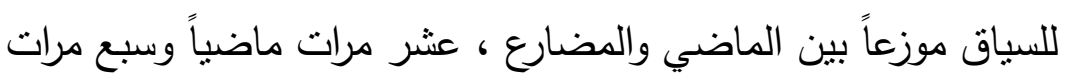

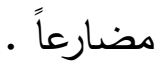

وورد من الصور الصرفيه لهذا الفعل في النصوص القرآنية موضوع ، إنهارع

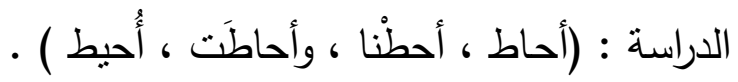
وفيها يلي عرض لدلالات تلك الصور من خلال سياقا ت الآيات القرآنية الثالية: - - n

1 - دلاة معنى حركة الا لنفاف الحسي ويظهر هذا المعنى في الثناهد الآتي: (( إِنّا اعتدنا للظالمين ناراً أحاط بهم سُرَادقُقُها )) الكهف 29 
2 - انقال الدلالة من الحسوس إلى الدجرد ، ويظهر هذا ال معنى في

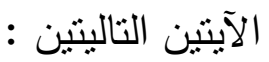

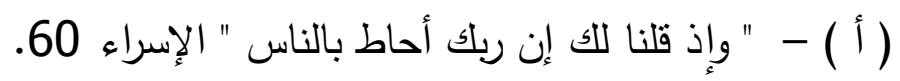

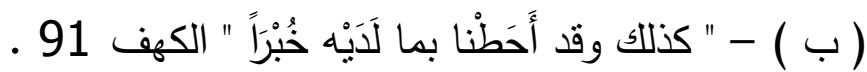

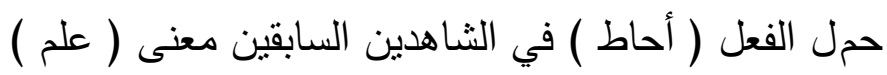

3 - انتقال الدلالة من المادي إلى المعنوي : وذلك على نحو ما يظهر

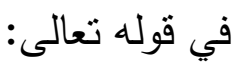

( أ ) - "بلى من كسب سيئة و أحاطت به خطيئته نُولئلك أصحاب

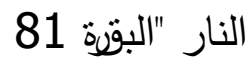

( ب ) _ " و أحيط بثررهفأصبح يقلب كفيه على ما أنفق فيها "

$$
\text { الكهف } 42 .
$$

حمل الفعلان (أحاطت، أحيط) في الثناهدين العابقين معنى "هلك" .

تدو ر دلالة الفعل ( نبذ ) في المعجمات حول دلالة الطرح في القوة

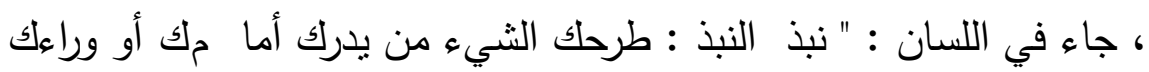

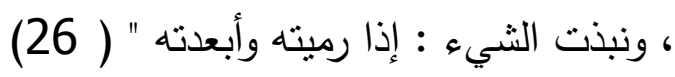

$$
\text { عدد المرات التي ورد فيها الفعل : }
$$

ورد الفعل عشر مرات ، ثماني مرات ماضياً ، ومرة مضارعاً ، ومرة

ومما ورد في الساق موضوع البحث بدلالة حسية حركية بمعنى الطرح بعنف

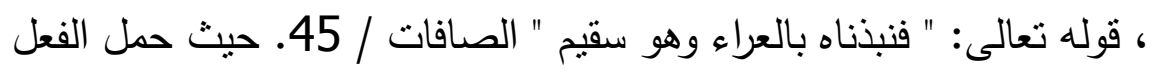
( نبذ ) معناه الحقيقي. 
وظهر معنى انتقال الدلالة من المادي إلى المعنوي في الثاهدين التاليين :

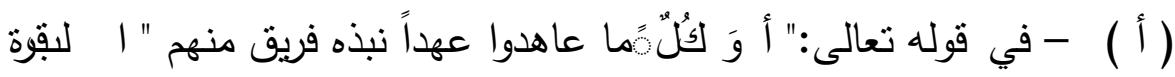
100

حمل الفعل ( نبذ ) معنى نقض ، إذ نقض الكيهود عهودهم ومواثيقهم.

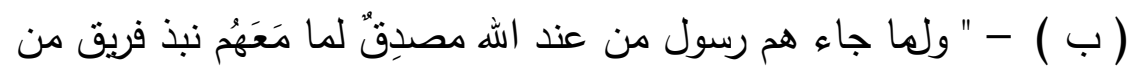

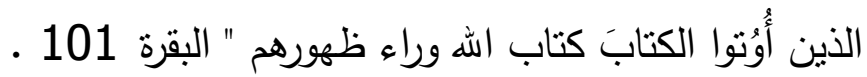

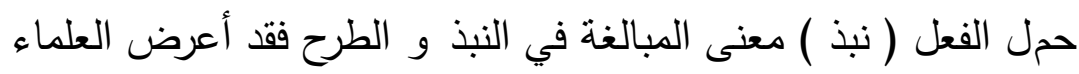

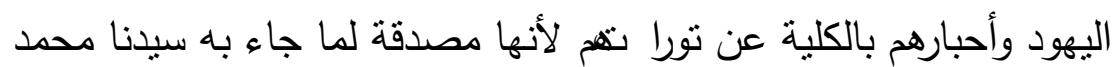

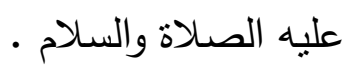

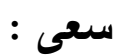

يقع الفعل ( سعى ) ضمن الحركات الانتقالي ة التي تتسم بالسرعة إذا ما قورنت بالمشي والزحف وسائر الحركات البطيئة ، وتدور دلالة الفعل الفل

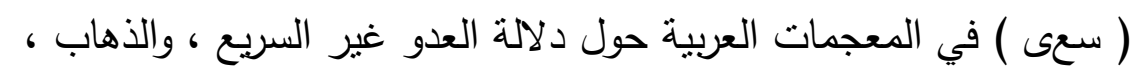
جاء في اللسان : والسعي : عَدْرٌ دون الثَد ــوقال الزَجَّاج :

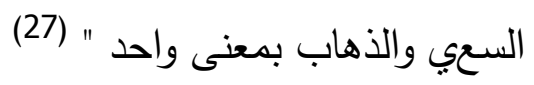
عدد المرات الني ورد فيها الفعل :

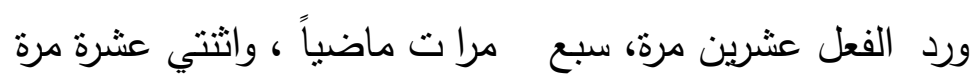

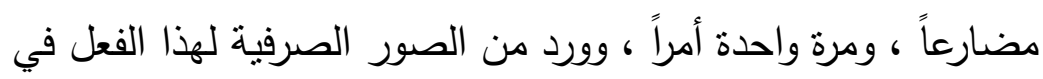

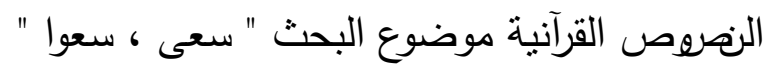

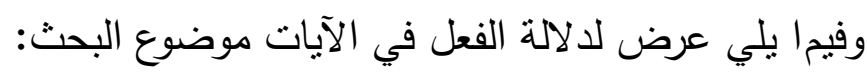
1 - تخصيص الدلالة كما في الثاهدين الآتيين:

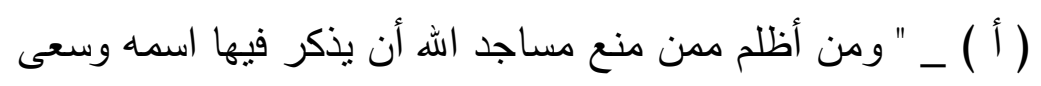

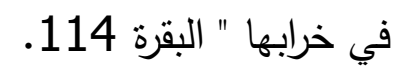


( ب ) - " وإذا تولى سعى في الأرض ليفسن فيها ويهلاك الحرث "

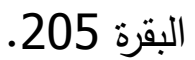

يلاحظ أن الفعل ( سعى ) حمل في الثـاهدين السابقين

$$
\text { معنى: [عمل]. }
$$

2 - انقال الدلالة من المادي إلى المعنوي ويظهر ذلك في قولهـ تغلى: "

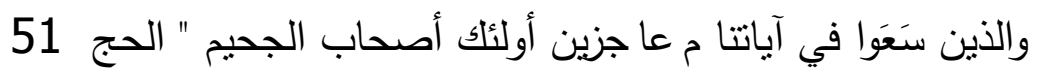

$$
\text { . فالفعل (سعوا ) معنى كذفبوا. }
$$

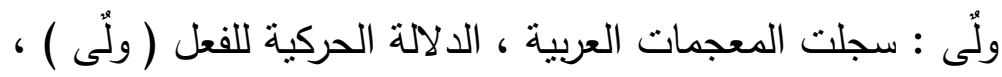

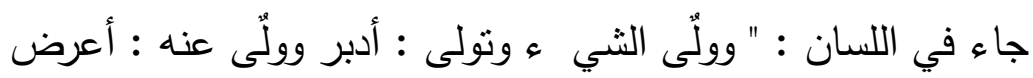

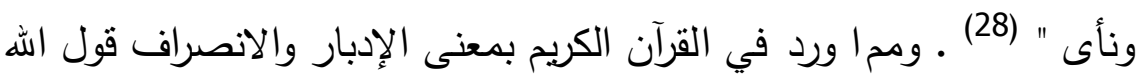

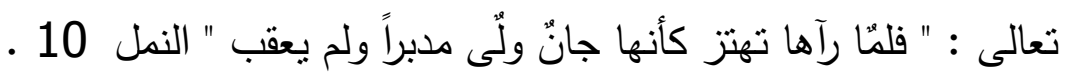
عدد المرات التي ورد فيها الفعل : ورد الفعل ثلاثين مرة ، انثتي عشرة ماضياً ، و لغلاث عشرة مرة

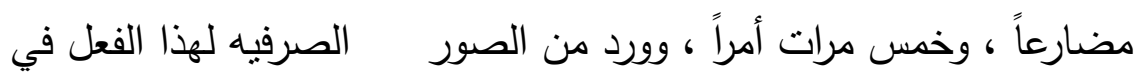

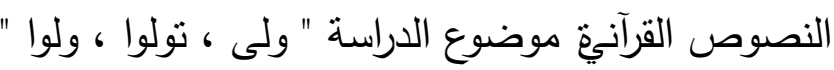
وفيما يلي عرض لدلا لات الفعل الماضي من خلال سياقات الآيات القرآنية

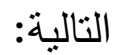

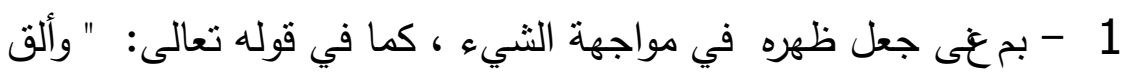

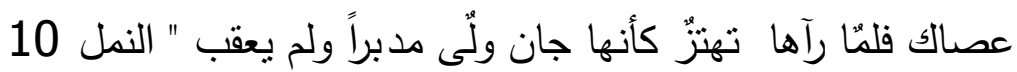
2- تخصيص الكلالة ويظهر ذلك في الثواهد القرآنية الآتية:

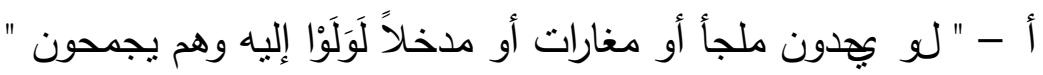

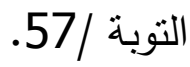
حمل الفعل (لولًَّْا ) معنى لأقبلوا مسرعين. 
ب- " سريقول السّقهاء من الناس ما ولا هم عن قبلتهم التي كانوا عليها" البقزة /142. فالفعل " ولاهم ، حمل معنى صرفهم وحولهم.

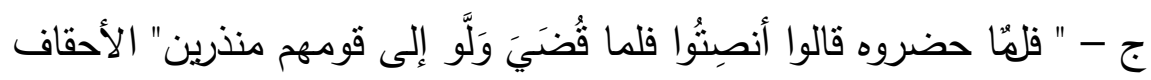
/29حمل الفعل ( ولُّوا ) معنى رجعوا إلى قومهم . أنى : n

يقع الفعل ( أنى ) في مجال الحركة الانتقالية الدالة على الإياب ، وتدور دلالة مادة الفعل ( أتى ) في المجمات حول معنى المجيء ، جاء

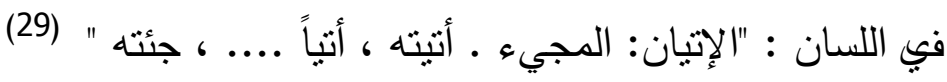
وينتمتع الفعل بمدى دلالي واسع في مجال الإت ميلن ، والمجيء المعنوي

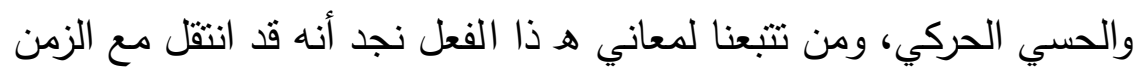

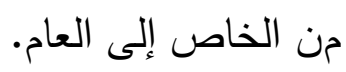

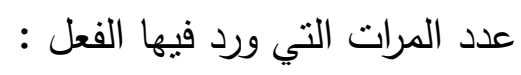
ورد الفعل مائتين وسبعاً وخمسين مرة ،سبعاً وأربعين مرة ماضياً ، ومضارعاً

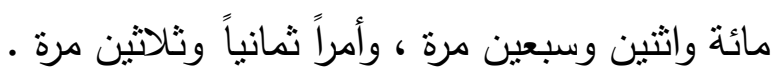

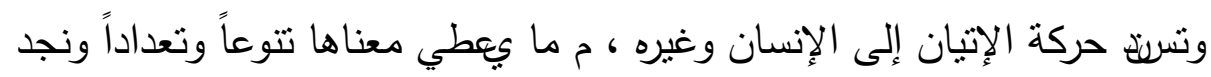
من الصور الصرفيه لهذا الفعل في السياقات القرآنية موضوع اليعثى :

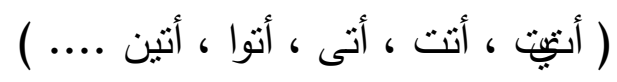

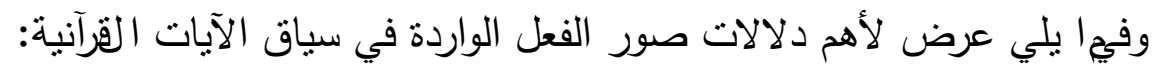

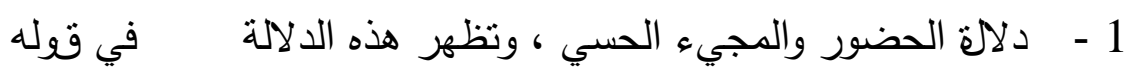
تعالى :

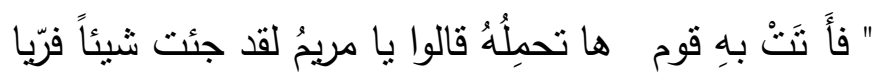

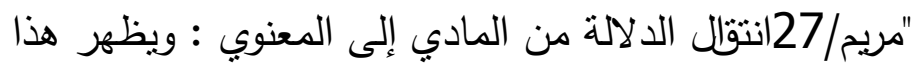

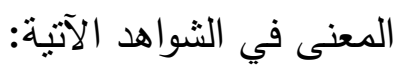




$$
\text { ( أ ) - " وهل أناك حديث موسى " طه/ } 9
$$

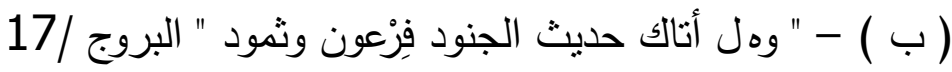

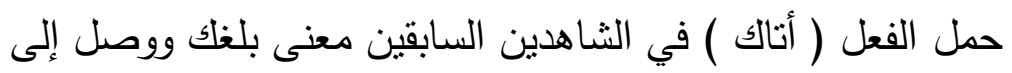

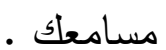

( ( ) - وح مل الفعل ( أتاهم ) معنى مجيء البرهان والحجة

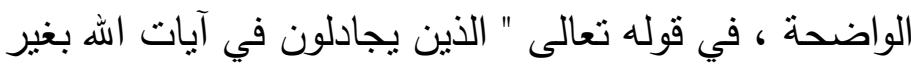

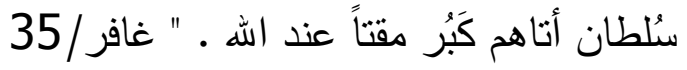
3 - تأرجح المعنى لين المادي والمعنوي : وتظهر دلالة هذالة هذا المعنى في

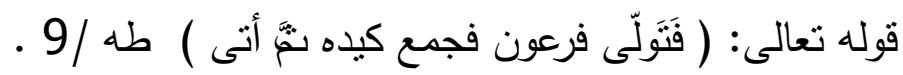

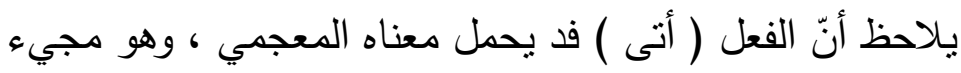
فرعون إلى المكان المحدد بينه وبين سيدنا موسى عليه السلام ، وقد يحمل لهل

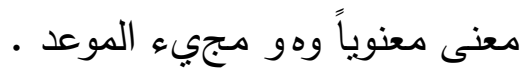

4-انثال الدلالة من الكل إلى الجزء : وتظهر هذه الدلالة في قوله

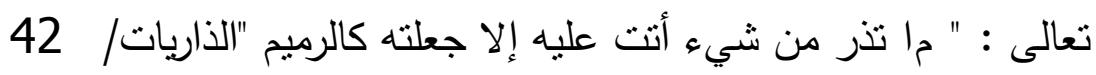
، وفي قوله تعالى: ولا يفلح الساحر حيث أتى " طه/ 69 ـ .

فالفعل في الآية الأولى حمل معنى مرت ، وفي الثانية حمل الفعل (

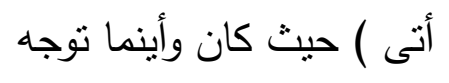

5 - انتقال الدلالة إلى المعنى المجازي المعنوي ، ويظ هر هذا المعنى

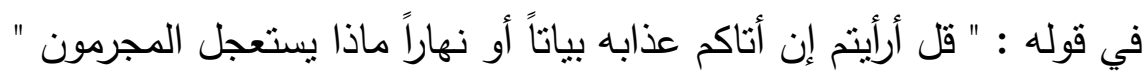

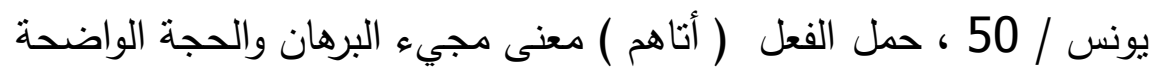

4 - تخصيص الدلالة:وتظهر هذه الدلالة في سياق الآيات القرآنية الآتية: 
( أ ) - " ولا تحسبنً الذنين يفرحون بما أنوا ويحبّون أن يحمدوا بما

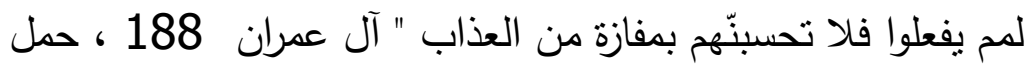

$$
\text { الفعل ( أتوا ) معنى: فلعلوا. }
$$

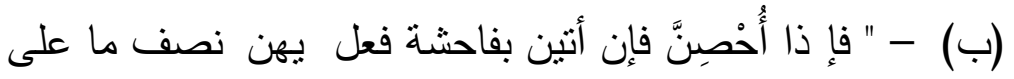
المحصنات من العذاب " النساء 25.

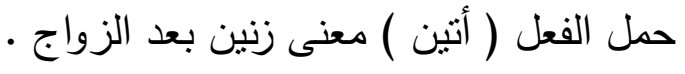

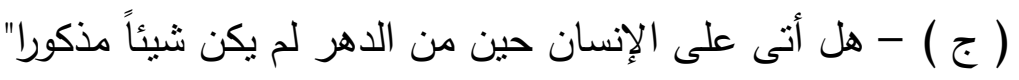
الإنسان 1. دل الفعل ( أنى ) في سياق الآية القرآنية على معنى أنه قد مضى الإنى

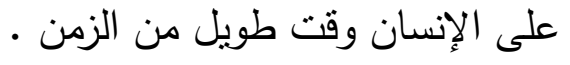
حجَّ: يقع الفعل (حجّ ) في مجال الحركة الانتقالية المرتبطة

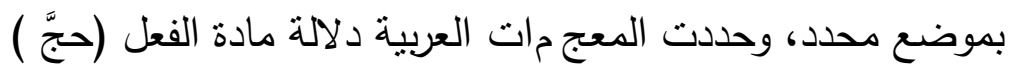
بأنها " حجَّ إليه حجاً : قدم وحجّ المكان ، قصده " (30) .

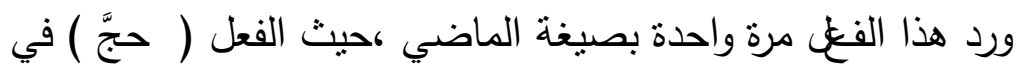

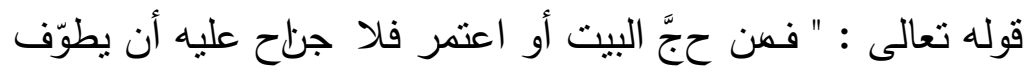

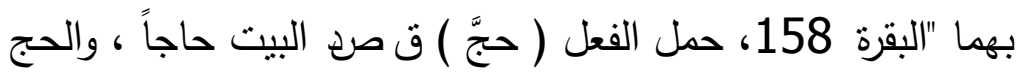
ركن من أركان الدين الإسلامي محدد في مكان وزمان للعبادة فتخصصت دلالة الفعل في الإسلام. ركن الإن الاني

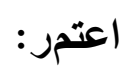

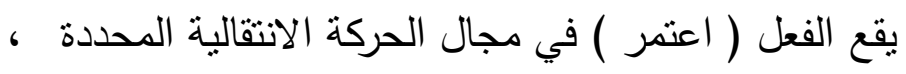

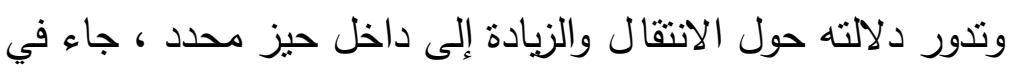


اللسان :

"اعتر : عمر يعمر ، وذكرت معاجم اللغة أن العَمْر والعُمُر والعُمْر : هو الحياة والجمع أعمار ، واعتمره : زاره (31) .

وورد الفعل (اعتمر) مرة واحدة بصيغة الماضي في قوله اعله

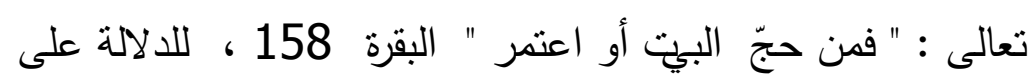
الانتقال من العام إلى الخاص، فالعمرة في الإسلام غيرها في الجاهلية ففي الجاهلية لم تكن لها شروط محددة ، أما في الإسلام فقد ربطت بين معنى الزبارة وبين مفهوم العبادة والسّنة النبوية فرّقت

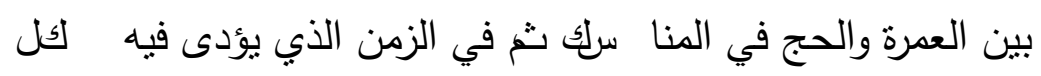
منهما. رجع : يدور معنى مادة الفعل ( رجع ) حول الع ود إلى ما كان منه البدء

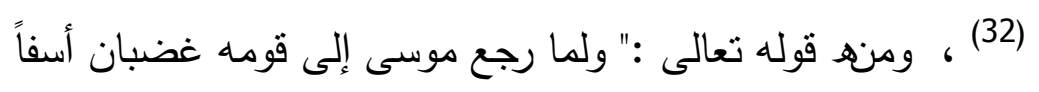

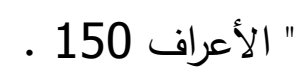
-

ورد الفعل تسعاً وسعين مرة ، إحدى عش رة رة مرة ماضياً ، وخمساً

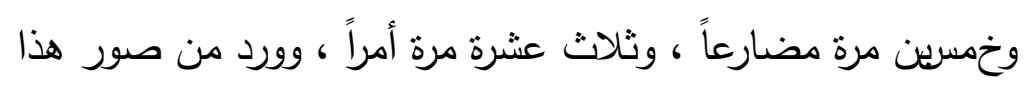
الفعل في الآيات موضوع البحث :" رجعتم ، رجعك ، رجعوا ، رجعت " وفيما يلي عرض لمعاني تلك الصور من خلال السياقات التي وردت بها

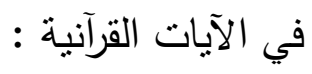


(1) - دلالة العودة : ( الدلالة العامة للفعل ) ، و تظهر هذه الدلالة في الثاهدين التاليين : " فمن لم يجد فصيام ثثلاثة أيام في الحج وسبعة إذا رجعتم " البقرة 196.

( ب ) - " فإ ن رجعك الله إلى طائفة منهم فاستأذنوك للخر و وج فقل لن تخرجوا معي أبداً " التوبة 83. (2) - انثقال الدلالة من المادي إلى المعنوي : وتظهر هذه الدلالة في قوله تعالى : " فرجعوا إلى أنفسهم فقالوا إنكم أنتم الظالمون " الأنبياء /64 حمل الفعل ( رجعوا ) معنى الرجوع إلى عقولهم والتفكر بقلوبهر • (3) - تأرجح بين الدلالة المادية والمعنوية : ويظهر ذلك في قوله تعالى :

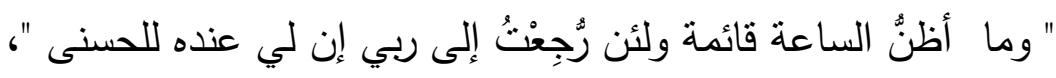
فصلت /50.

حمل الفعل ( رجعت ) معناه المعجمي ، ويمكن أن يحمل المعنى المعنوي. -

أثب تت المعجمات العربية الدلالة الحركي ة الموضعية للفعل ( زلّ )

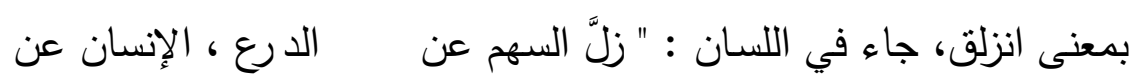

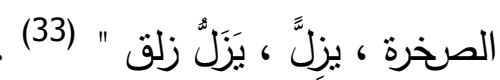

وورد الفعل مرتين ، مرة ماضيًاً ، وأخرى مضارعاً ، ودلّ الفعل برل الماضي على انتقال الدلالة من المادي إلى المعنوي ، في قوله تعالى: " فأن

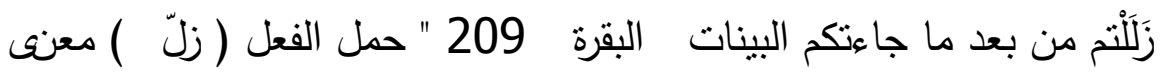
انحرفتم عن الاخول في الإسلام • زلزل :

سجل ت المعجمات العربية الدلالة ال لحركية لمادة الفعل (زلزل ) بمعنى الحركة العظيمة والإزعاج الثديد ، ومنه زلزلة الأرض (34) . 
ورد الفعل ( زلزل ) ثلاث مرات بصيغة الماضي ، ولا يخرج في سياقات الآيات القرآنية عن دلا لته المعجية ، حيث يدو ر ر معناه فيها حول دلالة الاضطراب بشدة ، ويعتبر ملمح القوة أهم ملمح يميز دلالة هذا الفعل ، ونجد من الصور الصرفيه لهذا الفعل في النصوص القرآنية موضوع البحث : ( زُلْزِ لَكَ ، زُلْزلوا ..) وفيما يلي عرض لمعاني تللك الصور من خلال

سياقات الآيلت القرآنية .

1 - دلاة الاضطراب بشدة ، الدلالة العامة للفعل ، وإليها تعود الدلالات

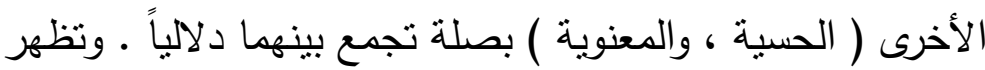
هذه الدلالة في السياق الآتي : " إذا زُلزِلت الأرض زلزاله الـ " الزلزلة

حمل الفعل (زلزلت ) معناه المعجمي ، وفي ال فعل تصوير لمشاهد القيامة على الأرض وجاء بصيغة الماضي ليدل عل حتمية الوقوع 2 - انتقال الدلالة من المادي إلى المعنوي : وذلك على نحو ما بظهر

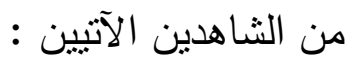

أ - " هناللك ابتلي المؤمنون وزلزلوا زلزالاً شديداً " الأحزاب 11 . ب - " ولّمّا يأتكم منل الذين خلو ا من قبلكم م سنهم البأساء والضراء وزلزلوا " ـ البقرة 214 .

حمل الفعل ( زلزلوا ) في الآيتين السابقتين معنى زعزعوا فهي زلزلة ناجمة عن اضطراب بالقلوب .

\section{مسنَّ : n}

تدور دلالة مادة الفعل ( مسّ ) في المعجمات حول معنى اللمس ، جاء في اللسان : مَسِستُه بالكسر ، أمسه مساً ومسيساً : لمسته ، هذه اللغة الفصيحة ، ومسسته، بالفتح أمسه بللضم لغة " (32) 


\section{عدد المرات التي ورد فيها الفعل :}

ورد الفعل ستاً وخمسين مرة ، ماضياً ثمانياً وعشرين مرة ،ومضارعاً

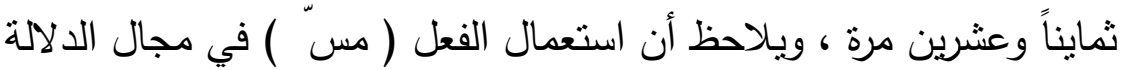
الحركية الحسية قليل ، ن شاع استعماله مجازاً بدلالات تدور حول معنى

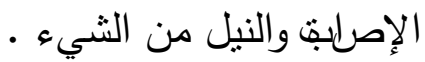

وفيما يلي عرض لسياق الآيات القرآنية التي ورد بها الفعل ( مسّ ) 1 - تخصيص الدلالة: وبظهر هذا المعنى في سياق الآية الآتية : " أم حسبتم أن تدخلوا الجنة ولمَّا يأتكم منل ال ذين خلوا من قبلكم

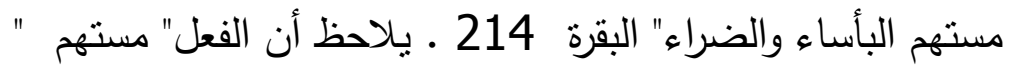
حمل معنى أصابتهم الثدائد والنوائب ، والمحن ، وكذا في سائر الآيات التي ورد فيها الفعل (مسّ) فقه حمل معنى أصاب ، سواء أكانت الإصابة مادية أم معنوية ،كما في قوله تعالى :" إن يم سسكم

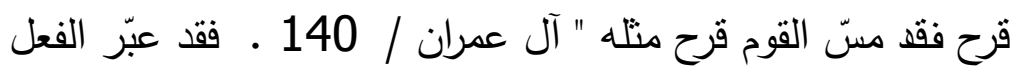
مسّ في الآية السابقة عما أصاب المسلمين من قتل وجرح وشعور بالانكسار في موقعة أحد . مبن الهابه

حدد ت المعجمات العربية دلالة الفعل ( هاجر ) بأنها ضد الوصل ، جاء في اللسان " الهجر : ضد الوصل "و حول هذه الدلالة العامة تدور دلالات المادة المتتوعة، ومن بين هذه الدلالات الدلالة الحركية ، جاء في

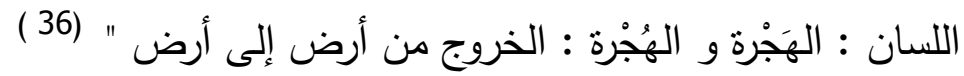
عدد المرات الثي ورد ليها الفعل : 
ورد الفعل ست عشرة مرة ، إحدى عشرة مرة ماضياً ، وخمس مرات

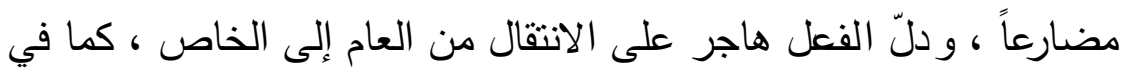

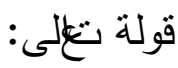
" إن الذين آمنوا والذين هاجروا وجاهدوا في سبيل الله أولئك برجون رحمة اله

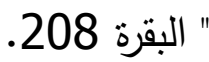

ويلاحظ أن دلالات الفعل الماضي لم تخرج في جميع الآيات عن الذين

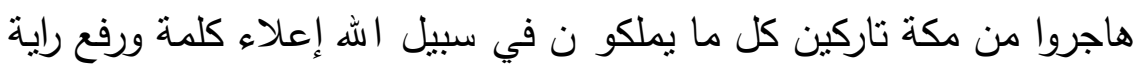

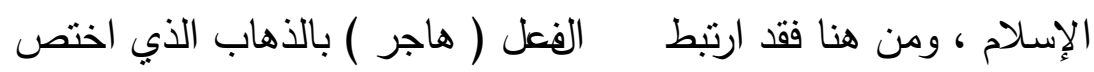

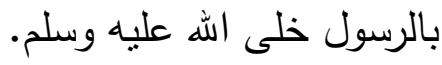
بلغ: بلغ

تدو ر دلالة مادة الفعل ( بلغ ) في المع جمات حول معنى الانتهاء ، المان

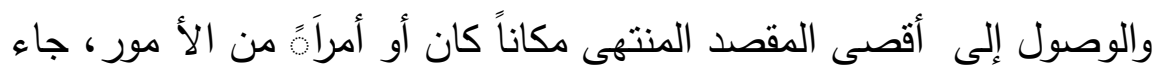

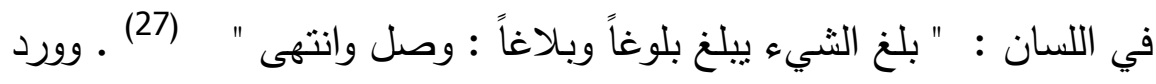

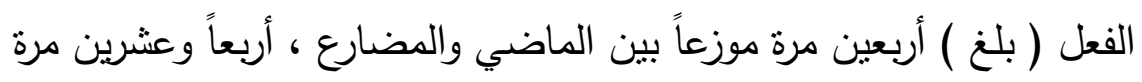

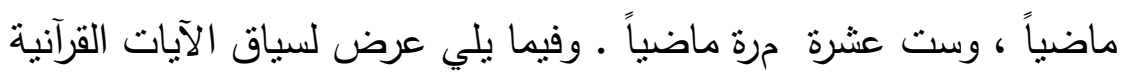

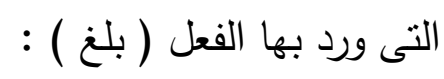
1 - ورد في القآن الكريم بالمعنى الحركي الحسي الذي ينتهي إلى ثبات

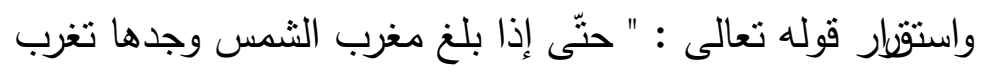

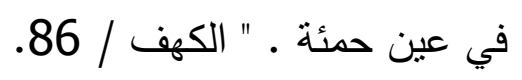
2 - انثقل الدلالة من الماد ي إلى المعنوي ، وذلك على نحو ما يظهر

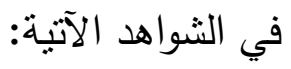
( أ ) - "فإ: ذا بلغن أجلهن فلا جن الح عليكم فيما فعلن بأنفسهن

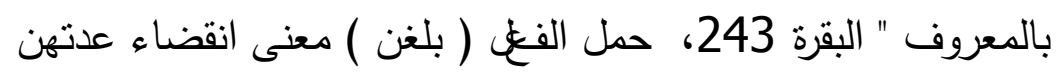


( ب ) - : " وإذ زاغت الأبصار وبلغت القلوب الحناجر " الأحزاب 10، حل الفعل ( بلغت ) معنى وصلت القلوب الحناجر وهو كناية عما لحقهم من خوف وذعر.

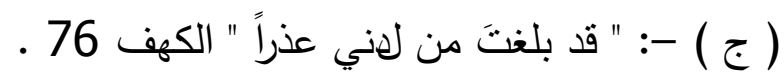
حمل الفعل ( قد بلغتَّ ) معنى احتملتتي وصبرت على مخالفتي للك كثيراً

3 - دلالة مجازية معنوية ، وتظهر في قولة تعالى : " فلمّا بلغ معه السّحي قال يا بنيّ إني أرى في المنام أني أذبحك " .الصافات / 10 حمل الفعل ( بلغ ) معنى ترعرع وشبَّ ووصل إلى السنّ الذي يمكنه منه أن يسعى مع أبيه.

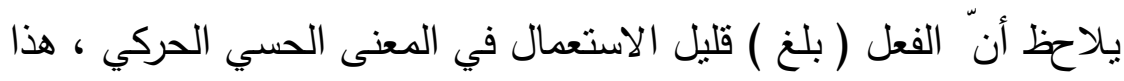
في حين أنّه للفعل ( بلغ ) شيوعاً ملحوظاً في الدلالات غير الحركية ، مثل الدلالة المعنوية والمجازية.

جاوز:

سجلت المعجمات العربية الدلا لة الحركية لمادة الفعل ( جاوز) وتدور حول معنى السير المرنبط بموضع محدد يتجاوزه السائر، وجاء في اللسان :

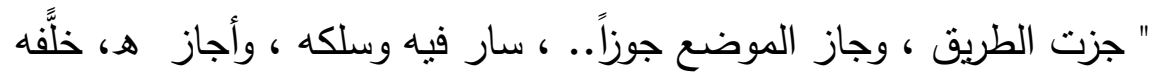
وقطعة " (38 ) وورد الفعل في القرآن الكربم خمس مرات ، أربع مرات ماضياً، ومرة مضارعاً. وحمل الفعل ( جاوز ) في القرآن الكريم :" فلمّا جاوزه هو و والذين آدنوا معه البقرة 249 ـ نفس الدلالة الحركية الانتقالية إلى وردت في المعجمات ، أي السير المرتبط بمك ان معين أو بموضع محدد يكون في قصد القائم بالسير أن يقطع تلك المسافة وأن يدرك هذا الموضع ويخلفه وركه. 
يقع الفعل ( مر ) في مجال الحركة الانتقالية الذاتية التي تصدر من

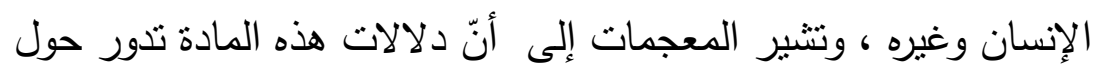

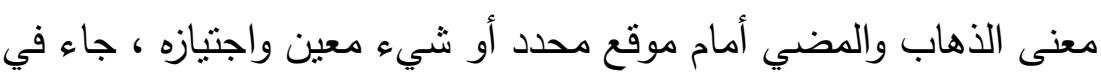

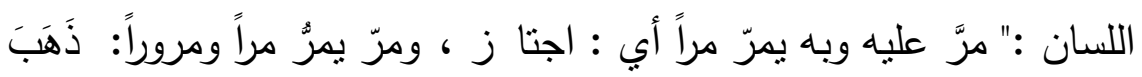

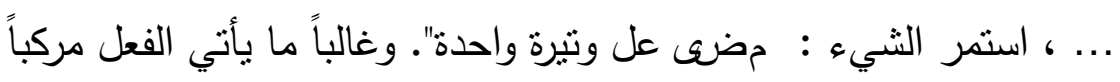

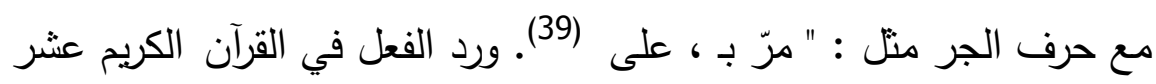
مرات ، سبع مرات ماضياً ، وثثلاث مرات مضارعاً.

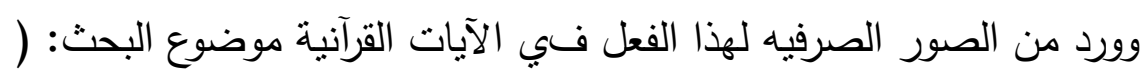

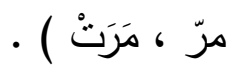

وفيها يلي عرض لأهم دلالات تلك الصور من خلال سياقات الآيات

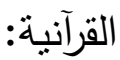

1 - دلالة المضي والذهاب أمام موضع محدد ، كما في قولة تعالى:

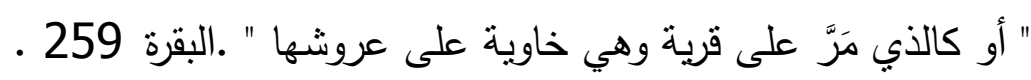

2 - انقال الدلالة من الهادي إلى المعنوي : كما في الثاهدين الآتيين :

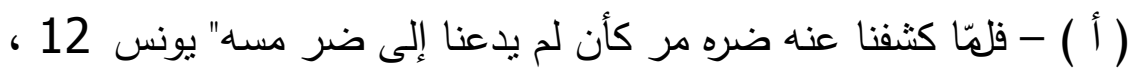

حمل الفعل ( مرّ ) معنى استمر على طريقته الأولى قبل أن يصيبه

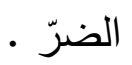

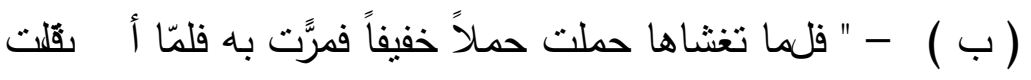

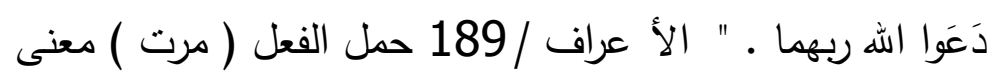

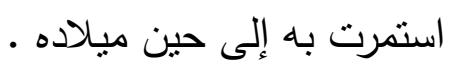

يقع الفعل ( عاد ) في مجال الحركة الانتقالية ، وتدور دلالة مادة الفعل 
في المعجمات حول معنى الرجوع إلى الثيء بعد الانصراف عنه ، جاء في : الثي اللسان :" عاد إليه يعود ع عودة وعوداً : رجع " (40). ويرد الفعل في سياقات الآيات القرآنية بنفس دلالته الحركية العجمية ، إذ إذ إداد

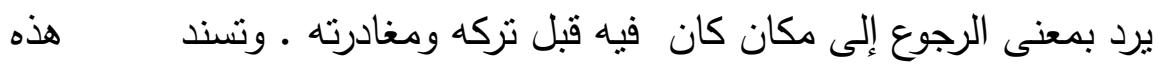

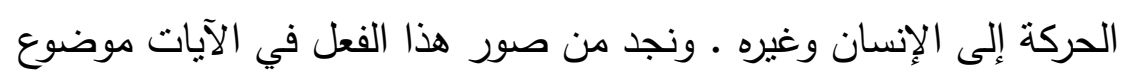

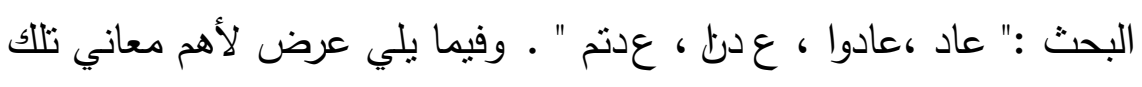

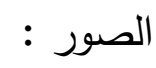

1 - دلالة الرجوع المعنوي ( مجازاً ) ، كما في الثواهد الآتية :

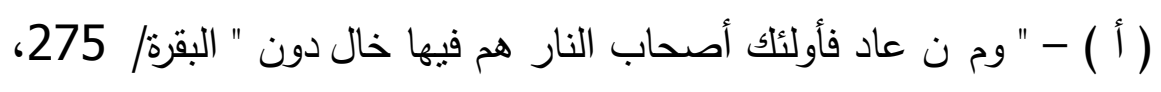

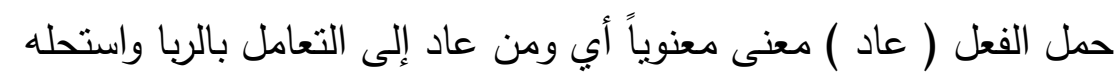

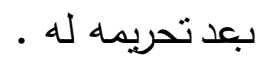
( ب) - " ولع ردُوا لعادواْ لِمَا نُهُهوا عنه و إنهم لكاذبون " الأنعام 28 ، أي

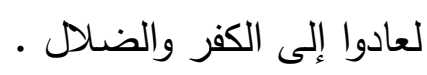

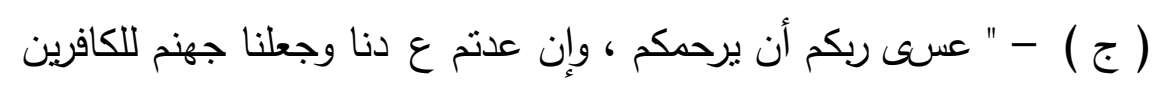
حصيرا "الإسراء / 8 ـأي عدنم إلى الإفساد والإجرام عدنا إلى الانتقام والعقبة.

ففي الثواهد التي سبقت وغيرها لم تحمل ( عاد ) ععاها المادي ، وإنما

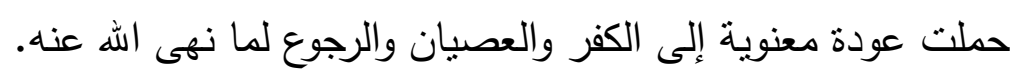

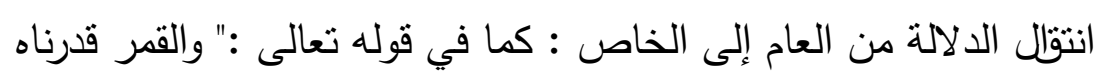

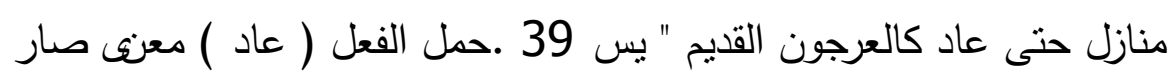
حمل :

تعود دلالات مادة ا لفعل ( حمل ) إلى الأصل الحسي الذي تثشير إليه

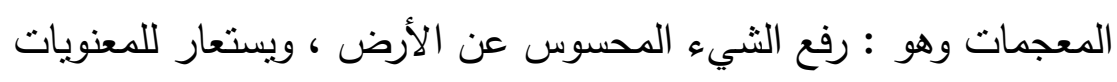


تنبيهاً لها بالأثقال المادية ، جاء في اللسان ، حمل الثيء يحمله حملاً ..

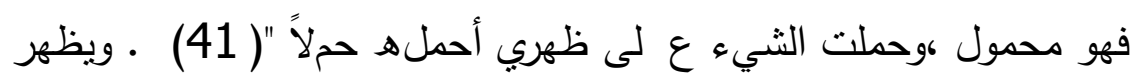

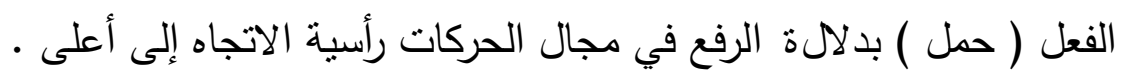

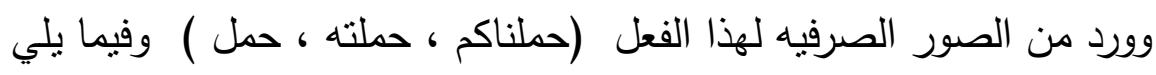
عرض لمعاني تلاك الصور من خلال سياقات الآيات القرآنية.

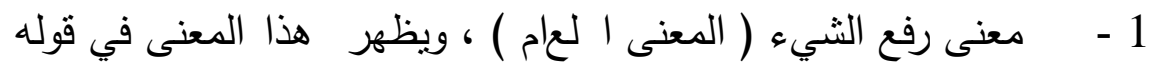

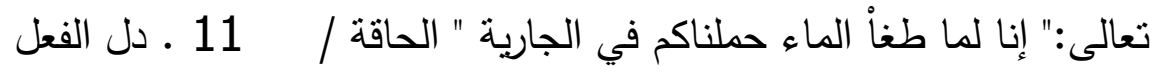

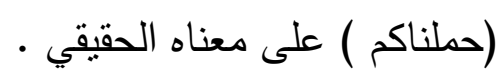

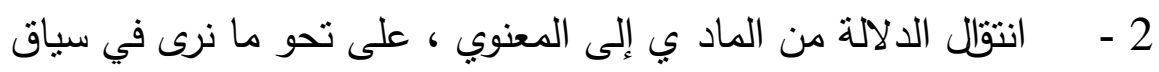
الآيتين التاليتين:

(أ ) - ربنا ولا تحمل علينا إصراً كما حملته على الذين من قلثنا "البقرة 386.

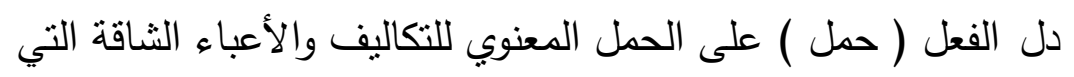

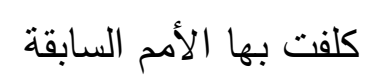

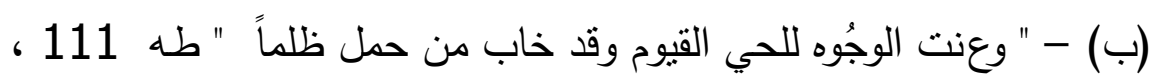

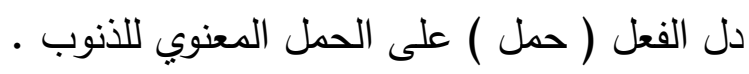

\section{نتايج الرحث}

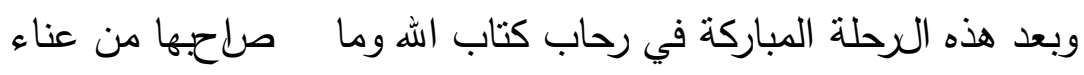
ومشقة توصل البحث إلى النتائج الآتية: 
1 - الغنى الحركي الذي تميز به الفعل الماضي في سورة البقرة وبعض

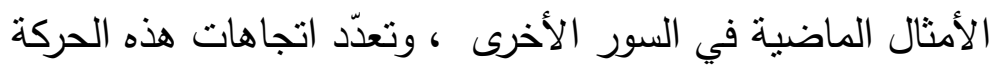

2 - الفغب الماضي الدال على الحركة في سورة البقرة وب عض آيات

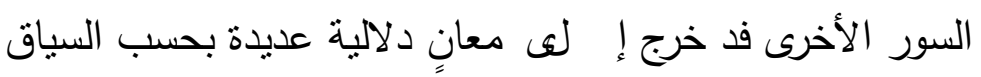
القرآني الذي ورد فيه وأهم هذه المعاني: 1 - 2 - تخصيص الدلالة 2 - 2

3 - - انثقال الدلالة من الكل إلى الجزء

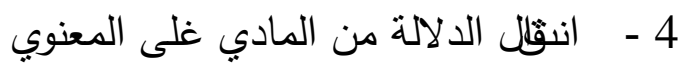

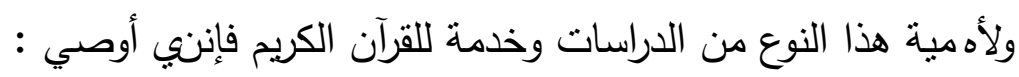

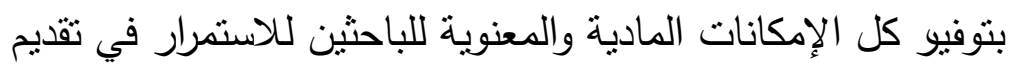

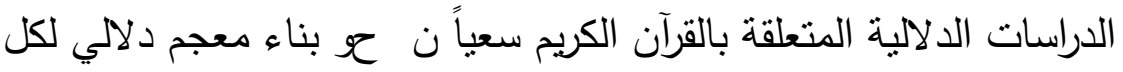

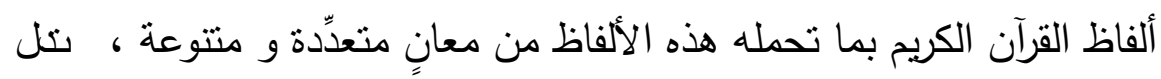
على عظمة هذا الكتاب وغناه بما يساعد على فهمه والعزل به. 
(1) - قسم النحاة العوامل إلى قسمين : لفظية ومعنوية ، وعدد الفعل أقوى العوامل ،إذ إنه ليس في اللغة فعل إلاّوله معمول هو الفاعل ، انظر الإنصاف ،

$$
\begin{aligned}
& \text { (2)- انظر : الكتاب 12/1 ، المقتضب : 80/4 . }
\end{aligned}
$$

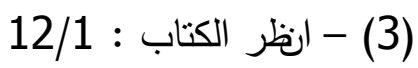

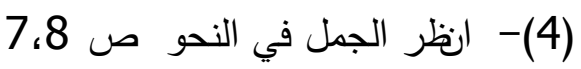

(5)- انظر : الاقتراح في أصول النحو ، السيوطي صـ صل 10 . (6)- انظر : وقديماً قال الفلاسفة : قد نُظرِر إليه على أنه حركة الفلك ، وأنه

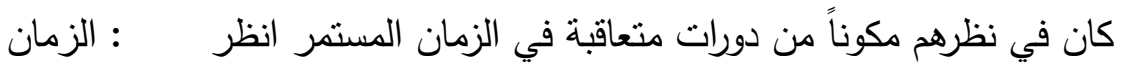
الوجودي ، د. عبد الرحمن بدوي ، ط 2، صن دمن دورت 52 - 53

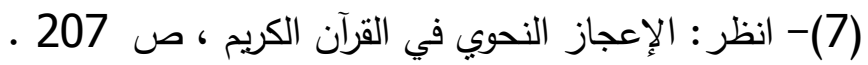

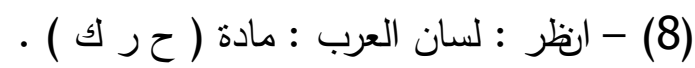

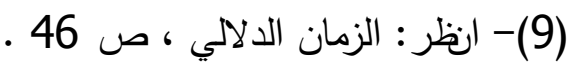

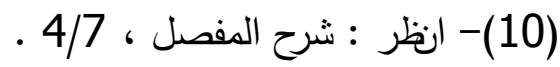

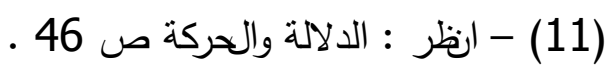

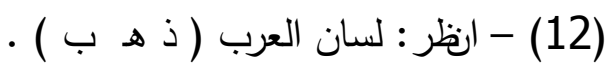

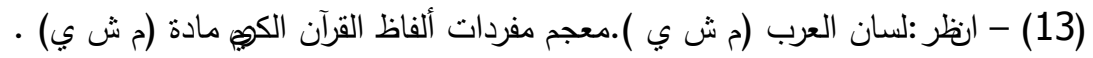

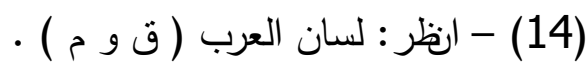

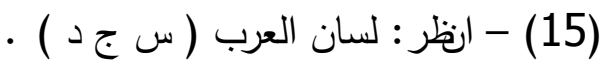

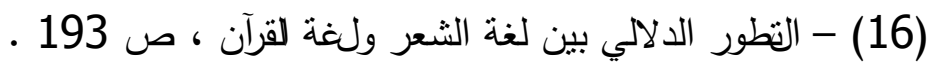

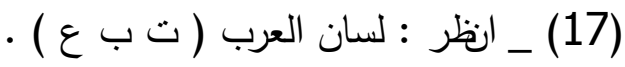

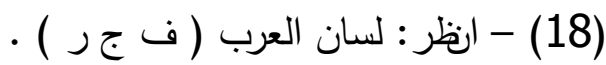

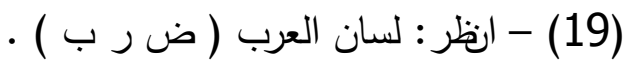

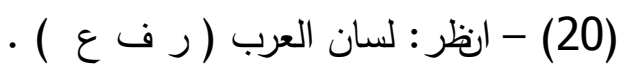

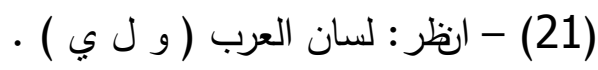




$$
\begin{aligned}
& \text { (22) - انظر : لسان العرب ( ج ى أ ) . } \\
& \text { (23) - انظر : لسلن العرب ( ف ت ح ) ) - (24) } \\
& \text { (24) - انظر : لسان العرب ( ك ت ب ) ) . } \\
& \text { (25) - انظر : لسان العرب ( ح و ط ) (26) }
\end{aligned}
$$

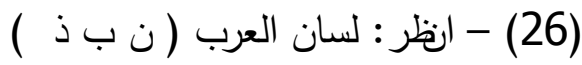

$$
\begin{aligned}
& \text { (27) - انظر : لسان العرب ( س ع عي ) (28) } \\
& \text { (28) - انظر : لسان العرب ( و ل ي لعزب ) }
\end{aligned}
$$

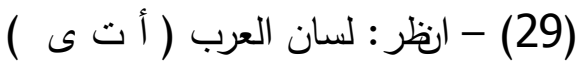

$$
\begin{aligned}
& \text { (30) - انظر : لهلن العرب ( ح ج ج ) ( }
\end{aligned}
$$

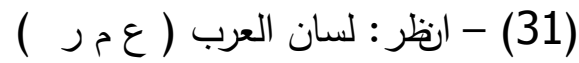

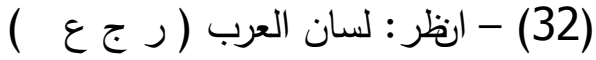

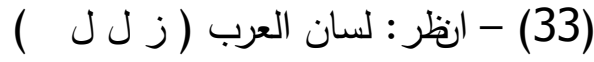

$$
\begin{aligned}
& \text { (34) - انظر : لسان العرب ( ز ل ل ال ) ل }
\end{aligned}
$$

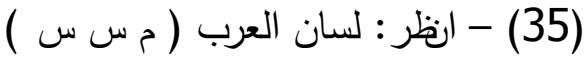

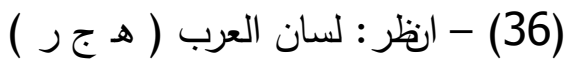

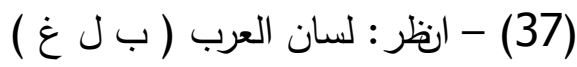

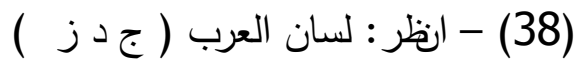

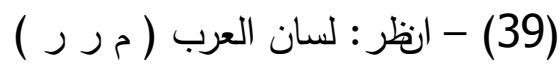

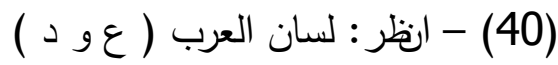

$$
\begin{aligned}
& \text { (41) - انظر : لسان العرب ( ح م ل ) }
\end{aligned}
$$




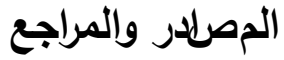

$$
\text { 1- الققآن الكريم }
$$

2- اين منظور : جم ال الدين محمد بن مكرم الأنصاري ، لسان العرب: ط / دار

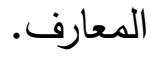

3 - ابن يعيش النحوي : شرح المفصل:عالم الكتب بيروت ، 1970 م

4 - الزجاجي : الجمل في النحو.تحقيق د / علي توفيق الحمد ، مؤسسة الرسالة بيروت ، الطبعة الخامسة ، 1417 هـ ـ العيد

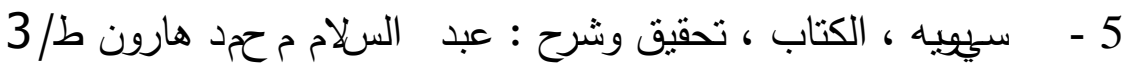
/ القاهرة ، مكتبة الخانجي 1988 م .

6 - السيوطي ، الاقتراح في أصول النحو. الطبعة الثانية ، حيدر أباد ، الهند

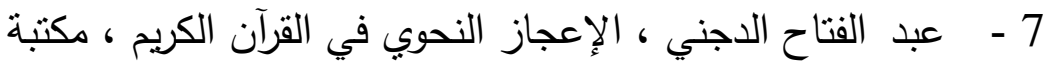

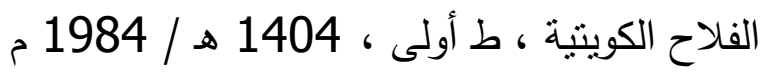

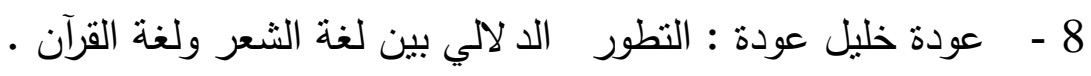
مكتبة المنار ، الزرقاء ، الأردن ، طبعة أولى 1405 هـ ، 1985

9 - كريم زكي حسام الدين: الزمان الدلالي : مكتبة ..... المصرية. ط ط

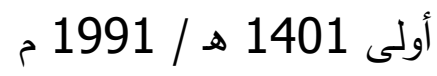

10 - محمد فؤاد عبد الباقي : المعم الدفهرس لألفاظ القرآن الكريم .د ار ار

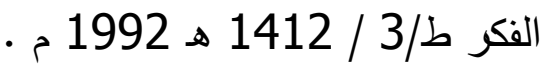

11 - محجد محمد داود ، الدلالة والحركة ، دار غريب ، القاهرة : 2002 